\title{
Multi-Scale Characteristics of Precipitation and Temperature over West Africa Using SMHI-RCA Driven by GCMs under RCP8.5
}

\author{
Abdoulaye Sarr \\ Agence Nationale de l' Aviation Civile et de la Météorologie du Sénégal (ANACIM), Aéroport LSS, Dakar, Senegal \\ Email: layesarr@mail.com
}

How to cite this paper: Sarr, A. (2017) Multi-Scale Characteristics of Precipitation and Temperature over West Africa Using SMHI-RCA Driven by GCMs under RCP8.5. American Journal of Climate Change, 6, 455486.

https://doi.org/10.4236/ajcc.2017.63024

Received: January 11, 2017

Accepted: August 20, 2017

Published: August 23, 2017

Copyright $\odot 2017$ by author and Scientific Research Publishing Inc. This work is licensed under the Creative Commons Attribution International License (CC BY 4.0).

http://creativecommons.org/licenses/by/4.0/

\begin{abstract}
In this paper, we use simulations from the Swedish Meteorological and Hydrological Institute (SMHI) regional climate model (RCM) version 3.5 (SMHIRCA3.5) following a multi-GCM boundary forcing approach. The model is run at a horizontal resolution of $50 \mathrm{~km}$ on the CORDEX-AFRICA domain. Key characteristics of precipitation, mean temperature and its extremes (minimum and maximum temperature) have been investigated over West Africa and on 3 designed sub-domains, the Sahel (SAH), the Senegal-Gambia (SEN) and the Gulf of Guinea (GOG). The analysis covers a historical period 1981-2005 and two future time slices, an intermediate term (IT) 2031-2055 and a fat term (FT) 2071-2095, under the Representative Concentration Pathways 8.5 (RCP8.5). The regional climate model RCA, forced by the reanalysis ERA-Interim, 6 CMIP5 GCMs and their ensemble, reproduces realistically the climatology of precipitation and temperatures over West Africa. Compared to observed datasets GPCP for precipitation and CRU for temperature, the ensemble outperforms both other GCMs and the verification model (ERA-Interim). The major biases in precipitation are the early onset over the Sahel and the little dry season (LDS), from mid-July to mid-September over the Gulf of Guinea, and a few models either overestimate and/or reflect rather poorly. The strong warming in extreme temperatures (minimum and maximum) combined with the drying mainly over Western Sahel (SEN) found in this study will very likely impact notably a vital sector like agriculture, both during the near and far terms.
\end{abstract}

\section{Keywords}

Downscaling, Scenarios, Climate Variability and Change, Onset, Seasonal Cycle, West Africa 


\section{Introduction}

The two last Inter Governmental Panel on Climate Change (IPCC) reports, AR4 [1] and AR5 [2] have demonstrated the fact that global warming, due to human activities, is a reality. This changing climate will continue to affect the whole world, and more severely, highly vulnerable regions like Africa. A lot of efforts are underway to reduce the climate change impacts, to help countries and communities resilient to the adverse effects of climate change and related extremes. This is particularly important in a region like West Africa, especially its northern part, known as Sahel. The Sahel has recorded one of the longest and most devastating droughts, stretching from the 1970s into the mid-1990s [3]. Key sectors of the economy, like agriculture including pastoralism and water resources were most affected.

The complexity of climate change leads to major uncertainties, and efforts to obtain more accurate information at regional and more localized levels can be challenging. This is essential when working for sectors like agriculture in West Africa. To complement Global Circulation Models (GCMs), mainly run at coarse resolutions, Regional Climate Models (RCMs) are increasingly being used in many regions of the world. This is, however, not the case in many African regions, including West Africa, although a few studies have used single RCMs to demonstrate their ability to simulate West Africa's climate features and climatology [4] [5] [6]. The fourth IPCC assessment report (AR4), in mainly Chapter 11, which reviewed regional climate projections globally [7], emphasized the limited amount of regional climate modeling information in West Africa, implying a high level of uncertainty on the expected changes in the climate of the region.

This triggered a more sustained momentum to develop coordinated multi-model experiments focusing on Africa in general, but more specifically West Africa. These efforts include the West Africa Monsoon Modeling Evaluation (WAMME) [8] [9] [10], the African Monsoon Multidisciplinary Analysis (AMMA) [11] and the Predictions of Climate Change and their Impacts (ENSEMBLES) [12]. While very useful, these strategies were not as coordinated as the IPCC CMIP3, and more recently, the CMIP5 program of IPCC AR5.

The World Climate Research Program (WCRP) has endorsed a new initiative, the Coordinated Regional Downscaling Experiments (CORDEX) for all land and "hot spots" areas like the Mediterranean region [13]. Africa is considered a priority area for the improvement of the levels of impact assessments derived from high-resolution climate simulations using CMIP5 AOGCMs. The program is split in two distinct phases. In the first part, the principal goal is to assess the capability of participating RCMs to simulate detailed climate patterns in Africa's various regions [14]. The participating RCMs, use ERA-Interim Reanalysis (ERAINT) as initial and lateral boundary conditions (IC \& BCs) and were run at $50 \mathrm{~km}$ horizontal resolution for the recent past, 1979-2008. Over West Africa, more detailed studies have been conducted, using these datasets, to investigate the mean 
climatology and its variability [15] and daily characteristics of precipitation and temperature [16] among others. Phase two of the initiative consists in running the same RCMs using ICs and BCs from CMIP5 OAGCMs for the historical period up to 2005 and projections up to 2100, using Representative Concentration Pathway (RCP) emission scenarios [17] [18].

In this study, we use the simulations from the regional climate model of the Swedish Meteorological and Hydrological Institute (SMHI) RCA version 3.5 [19] driven by the six CMIP5 GCMs (Table 1) that have a 365 days calendar, namely NorESM1-M, CNRM-CM5, CanESM2, MIROC5, GFDL-ESM2M, ECEARTH and the verification GCM ERA-Interim, here-after in the text NCC, ARP, CCC, MIROC, GFDL, ICH and ERA. We opt to only consider in this study the highest emission scenario RCP8.5, to better assess the potential impacts on a vulnerable region like West Africa.

We focus our study on the simulated rainfall and temperatures validated against observed dataset for a selected historical period (1981-2005) before looking at projected changes in two future time slices: 2031-2055 as near term (IT) and 2071-2095 the far term (FT) in order to obtain insights on likely changes in the climate over the region. Considering the importance of agriculture in the region of study, which is mainly rainfed, we added features like the seasonal cycle and the associated onset of precipitation. The long-term trends and inter-annual variability are also important for the regional agriculture, implying a need to explore how the models reproduce them on the targeted subregions. We have the Senegal-Gambia (SEN) domain, the western most part of Sahel considered as a "hot spot" in the IPCC reports and two others homogenous sub-regions, the Sahel (SAH) know to have a unimodal rainfall regime as SEN and the Gulf of Guinea (GOG) which exhibit a bimodal regime [15] (Figure 1).

In this work, we concentrate on the validation of the models and their ensemble on a historical period or recent past 1981-2005. This is a crucial first step, which helps to know how well the models simulations reproduce the observed base climate state of the region. Multi scale characteristics of key parameters for the agriculture will be explored prior to investigating future climate change pro-

Table 1. The regional climate model RCA used and the forcing General Circulation Models (GCMs), their names, origin and short name used in the text.

\begin{tabular}{cccc}
\hline MODELS & ORIGINE & TYPE & NAME IN TEXT \\
\hline RCA4 & Sweden & RCM & RCA \\
ECMWF-ERAINT & UK & GCM & ERA \\
NorESM1-M & Norway & GCM & NCC \\
CNRM-CM5 & France & GCM & ARP \\
CanESM2 & Canada & GCM & CCC \\
MIROC5 & Japan & GCM & MIROC \\
GFDL-ESM2M & USA & GCM & GFDL \\
EC-EARTH & European Consortium & GCM & ICH
\end{tabular}




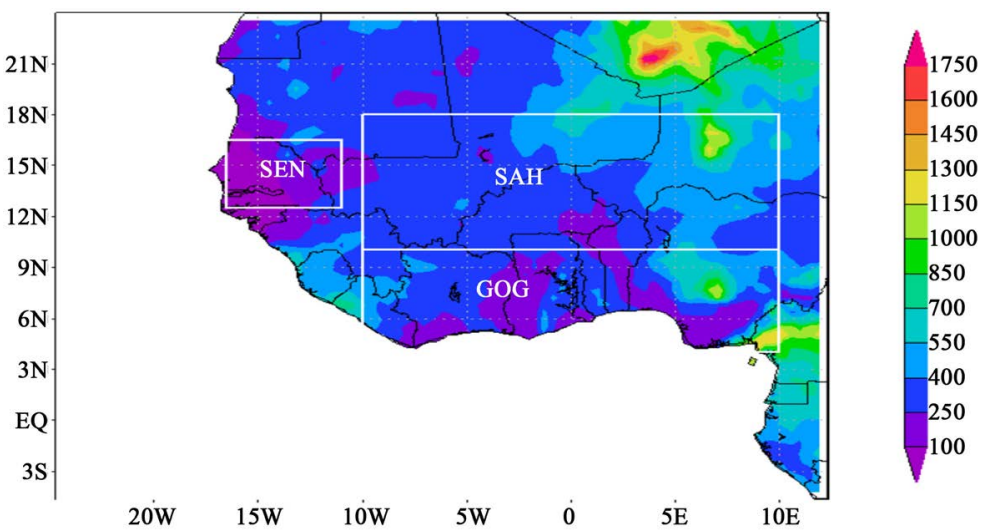

Figure 1. The West Africa domain to illustrate the 3 sub-regions: Sene-Gambia (SEN), Sahel (SAH) and Gulf of Guinea (GOG). The different countries (black contours) and the topography (shaded area in meters) are also represented.

jections. Section 2 is dedicated to the materials and methods employed in the investigation. In Section 3 the main results on the assessment, at multi-time and space scales, of the models simulation of the key climatic features over West Africa and the selected sub-domains, are presented. Prior to Section 5 on conclusion and discussions, Section 4 focuses mainly on climate projections under RCP8.5 for both the intermediate and far terms.

\section{Materials and Methods}

\subsection{Materials}

The Swedish Meteorological and Hydrological Institute (SMHI), regional climate model (RCM) RCA version 3.5 (Samuelsson et al., 2011), in the framework of the Coordinated Downscaling Experiment for Africa (CORDEX-AFRICA), is run at $50 \mathrm{~km}$ horizontal resolution over a wide area covering the whole of the African continent with initial and lateral boundary conditions from six Climate Models Intercomparison Project version 5 (CMIP5) Global Circulation Models (GCMs) and a verification simulation driven by ERA-Interim. The ERA run for the recent past started on $1^{\text {st }}$ January 1979 and end on $31^{\text {st }}$ December 2005. The first year is considered spin up time, implying that the analysis starts from $1^{\text {st }}$ January 1980. The seven GCMs are used to carry out simulations covering a transient period 1951 to 2100 , corresponding to a historical reference period 1951-2005 and future projection 2006-2100 using RCP8.5 scenarios. We use outputs at daily, monthly and yearly time scales from these simulations to study the performance of the models runs in simulating the historical period on critical parameters for rainfed agriculture over West Africa.

For precipitation, we use the monthly datasets of the Global Precipitation Climatology Project (GPCP) version 3.1 [20] and the daily GPCP-1DD v.1.2. [21] available from October 1997 as validation dataset. Concerning temperature (mean, minimum and maximum), the models outputs are validated against Climate Research Unit (CRU) version 3.2 [22], a gridded multi variables monthly 
dataset at a resolution of $0.5 \times 0.5$ degree (Jones et al., 2013), which uses station datasets known to have unequal density over Africa, in general, and more specifically over West Africa and its Saharan region, not well covered in stations. All models with a 365 days calendar are considered for the study.

\subsection{Investigation Methods}

As mentioned above, the analysis covers the West Africa domain and 3 subdomains (Figure 1), SEN, SAH and GOG. The first order analysis, mainly climatological, covers the historical period for both precipitation and temperature and aims at highlighting biases and the level of relationship with the validation datasets GPCP and CRU considered as observations. Trends and the interannual variability of rainfall over sub-domains is also investigate to better interpret and evaluate the projected changes during the near term (IT) and far term (FT). At higher temporal resolution, features like the seasonal cycle and the onset of the rainy season are studied to form the basis of a significant assessment of the models performance in simulating these critical characteristics of West Africa climate.

The last step investigates projected future climate, with a special emphasis on precipitation, considered as the most difficult parameter to simulate [5] [9] [10] [11]. Statistical methods employed include correlation, variability and error assessments using Taylor diagrams [23], linear regression and coefficient of variation for long-term trends for both historical and projected periods.

Another important climate behavior, to investigate in this study, is the northward/(withdrawal) movements of the Inter Tropical Convergence Zone (ITCZ), reflected in the annual cycle of precipitation. The final indicator, within the seasonal cycle used, is the onset of the rainy season, mainly over the Sahelian regions (SEN \& SAH), which have a unimodal rainfall regime [15] [24].

In this paper, we use the definition of the onset of the rainy season used by the West Africa AGRrometeorology HYdrology and METeorology Center (AGRHY MET) and adopted in all countries belonging to the Permanent Inter-States Committee for Drought Control in the Sahel (CILSS). The onset of the rainy season we use here is defined as the total accumulated rainfall over 3 consecutive days amounting to at least $20 \mathrm{~mm}$ and not followed by a dry spell exceeding 10 days respectively, in the next 30 days [25]. This definition is applied to the validation and verification dataset, the other GCMs and their ensemble in order to assess their skills in reproducing reasonably this strategic indicator for agriculture.

\section{Main Results}

\subsection{Climatology and Mean Bias}

\subsubsection{Precipitation}

First, we compare the validation and verification datasets by looking at spatial patterns of rainfall (Figure 2(a) and Figure 2(b)). ERA (Figure 2(b)) represents 

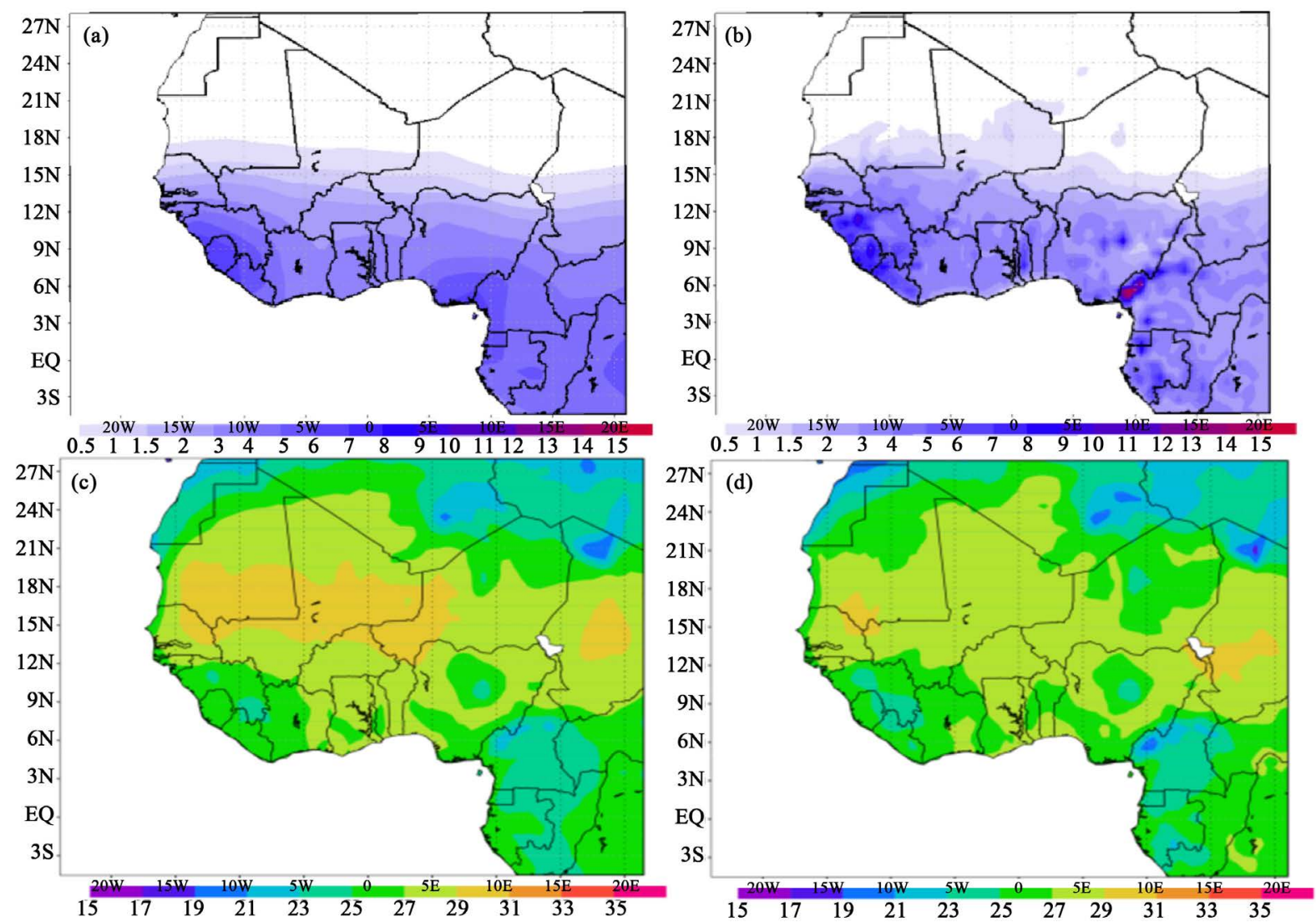

Figure 2. Annual climatology of: Precipitation for the reference period 1981-2005 over West Africa for the validation datasets (a) GPCP and the verification model ERA (b); Mean temperature $\left({ }^{\circ} \mathrm{C}\right)$ for the validation dataset CRU (c); and the validation model $\operatorname{ERA}(d)$.

fairly well the spatial patterns of rainfall climatology over West Africa compared to GPCP (Figure 2(a)).

The maxima of rainfall around the high topographic areas like the Guinea Highlands, JOS plateau and Mount Cameroon are well simulated by the run with ERA. ERA, with higher spatial resolution compared to GPCP even though regridded at $0.5^{\circ}$, shows more detailed patterns and even exhibits a bell shape over the Sahel region following the well-known structure of the ITCZ [26]. This demonstrates that RCA forced with supposed "observed" boundary condition, even with a domain not typically tailored for West Africa, can reasonable well reproduce the mean climate of a complex parameter like precipitation.

Detailed comparison with the model biases is shown in Figures 3(a)-(h). The highest bias (wet) is observed over GOG and over the Southeastern part of the domain mainly over Cameroon, Central Africa Republic, Gabon and Western Congo region. ICH and GFDL, respectively Figure 3(h) and Figure 3(g) exhibit the highest wet bias over GOG. Almost, all models underestimate rainfall patterns over the Southeastern part of the domain. Over the sahelian portion, rainfall climatology patterns are reasonably well simulated. MIROC (Figure 3(f)) exhibit the lowest bias over the whole domain. Generally, the climatology is fair- 

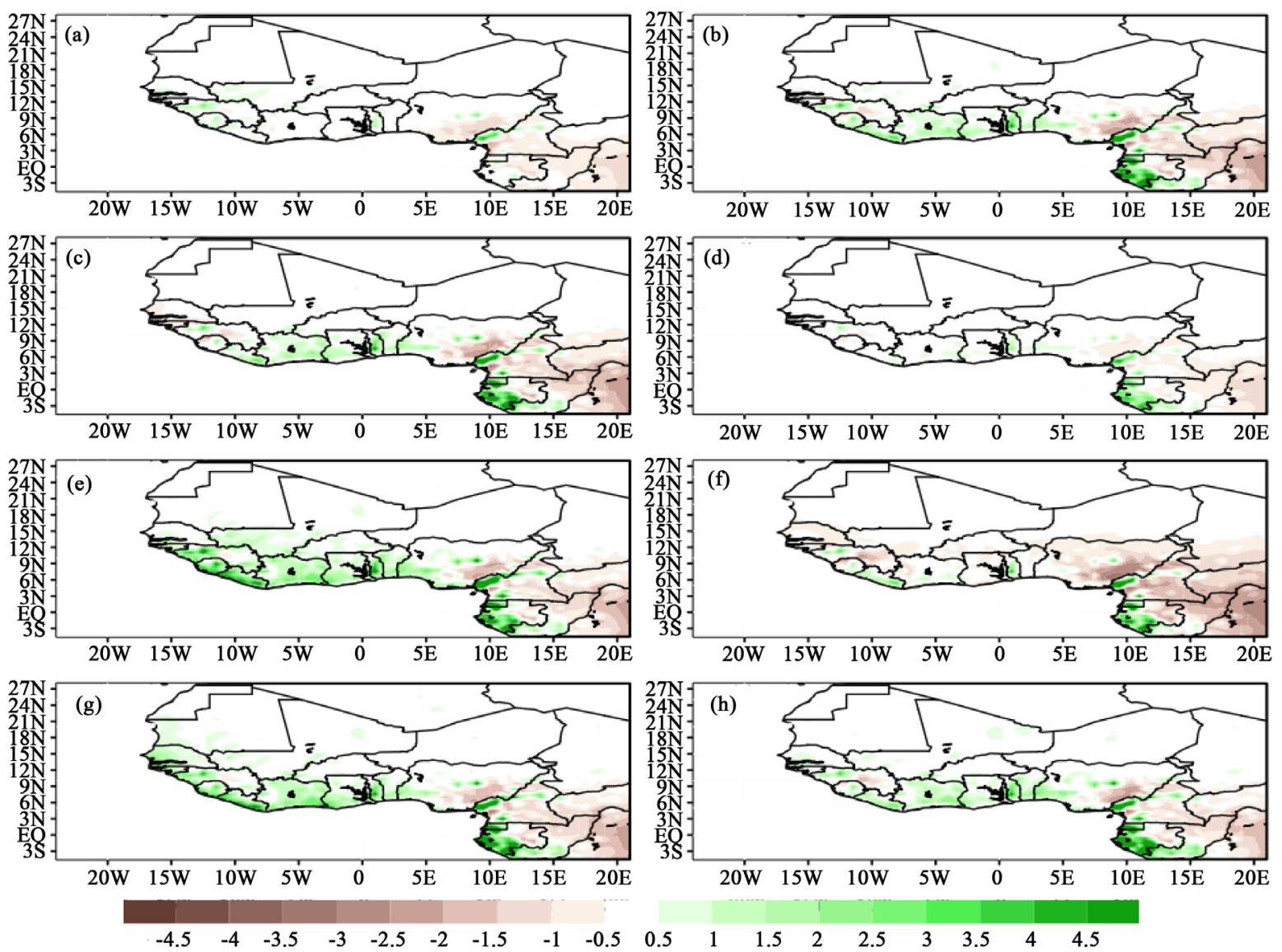

Figure 3. Precipitation mean bias (mm/day) relative to the validation dataset GPCP for (a) ERA; (b) MODENS; (c) NCC; (d) ARP; (e) CCC; (f) MIROC; (g) GFDL; and (h) ICH.

ly well simulated with biases mainly between -1 and $+1 \mathrm{~mm} /$ day from Senegal to Chad. Below $08^{\circ} \mathrm{N}$ the bias locally reaches $2 \mathrm{~mm} /$ day. ERA (Figure 3(a)) shows the lowest biases in all regions compared to other models including MODENS.

The wet biases, over southern Gulf of Guinea, are very likely induced by the respective GCMs known to miss propagating further north the ITCZ [27] [28]. This is shown in the seasonal cycle of precipitation mainly, the behavior over the Guinea coast and over northern Sahel (Section 3.2). The bias from individual GCMs is less apparent in the ERA (Figure 3(a)), result also noted in [15].

Apart from the biases in the climatology, we apply a Taylor Diagram (Figure 4(a) and Figure 4(b)) using monthly time series of precipitation and temperature (1981-2005) to better rank models using another temporal scale [23].

For precipitation (Figure 4(a)), known one of the most difficult parameter to simulated, amplified in tropical regions, mainly all simulations including the verification one and the ensemble have a correlation coefficient (cc) between 0.76 and 0.94. MODENS and ICH have the highest correlation, respectively 0.94 and 0.91 . The verification simulation ERA with a cc of 0.83 outperforms only MIROC which has the lowest $c c(0.76)$. Related to standard deviation, the highest values around 2.2 are noticed for MODENS and GFDF, while for others models the in- 


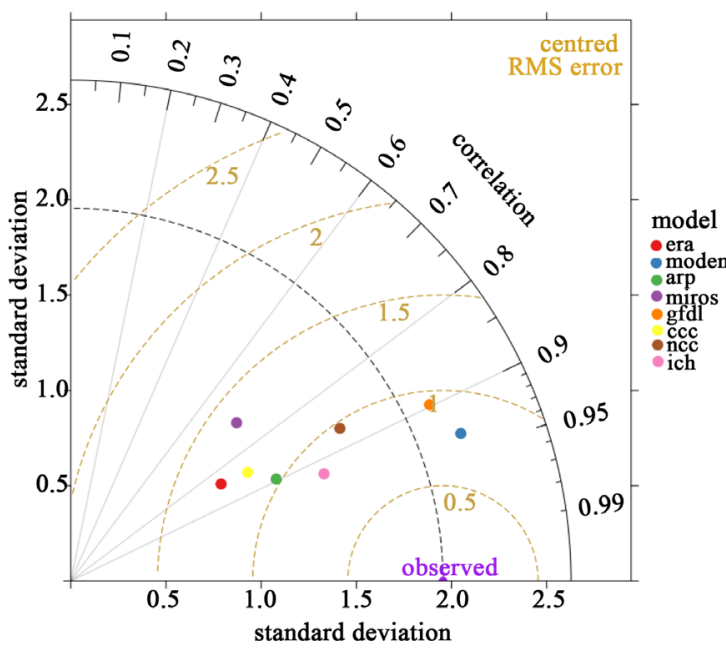

(a)

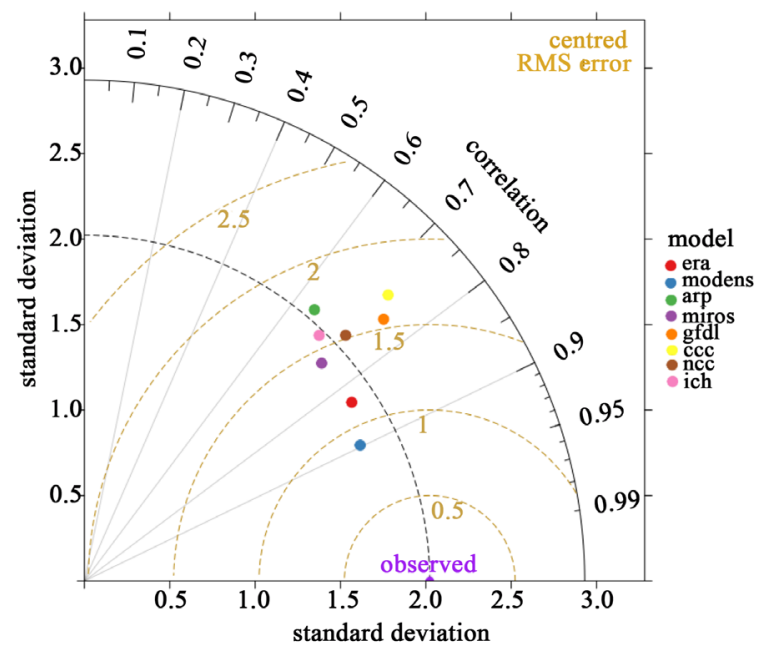

(b)

Figure 4. Taylor Diagrams to assess relationships with respect to the validation datasets GPCP for precipitation (a) and CRU for mean temperature (b). Correlation coefficients, standard deviations, and centered root mean squared differences are represented. The verification dataset ERA, the others models NCC, ARP, CCC, MIROC, GFDL, ICH and their ensemble MODENS are represented by distinct colors.

terval is between 0.8 for ERA and 1.5 for MIROC. These results are in agreement with other multi-modeling approaches.

The use of a multi-RCMs forced by ERA has shown, over West Africa, the ensemble outperforming individual RCMs [12] [14] [15] [27]. For our study, the same conclusion is found with MODENS outperforming individual GCMs and even the verification simulation ERA. This could suggest a relatively high weight to give to ensemble strategy.

In RCMs approach, differences could mainly be due to the internal dynamics and physics, while in this study they are very likely induced by the individual GCMs. This has been also shown in other studies [12] [14] [15] [27] [29]. RMCs have difficulty tracking the West Africa Monsoon (WAM) correctly when they fail to simulate, reasonably, the dynamic features like the Africa Eastern Jet (AEJ), the Sahara Heat Low (SHL), and the African Easterly Waves which are the smallest dynamic features that modulate rain producing systems in West Africa [27] [30] [31] [32]. Therefore, to explain biases, it is essential to investigate the ability of GCMs and RCMs in reproducing key features in the lower, mid and upper troposphere over West Africa, as well as surface properties at a more localized level [26].

\subsubsection{Temperature}

In this section, we look at mean temperature climatology spatial patterns (Figure 2) between the validation dataset CRU (Figure 2(c)) and the verification dataset ERA (Figure 2(d)). Even though, the spatial patterns look similar a noticeable difference is shown over northern Sahel and southern Sahara where ERA mainly under estimates mean temperature.

ERA (Figure 5(a)), MIROC (Figure 5(f)) and CCC (Figure 5(e)) have the 

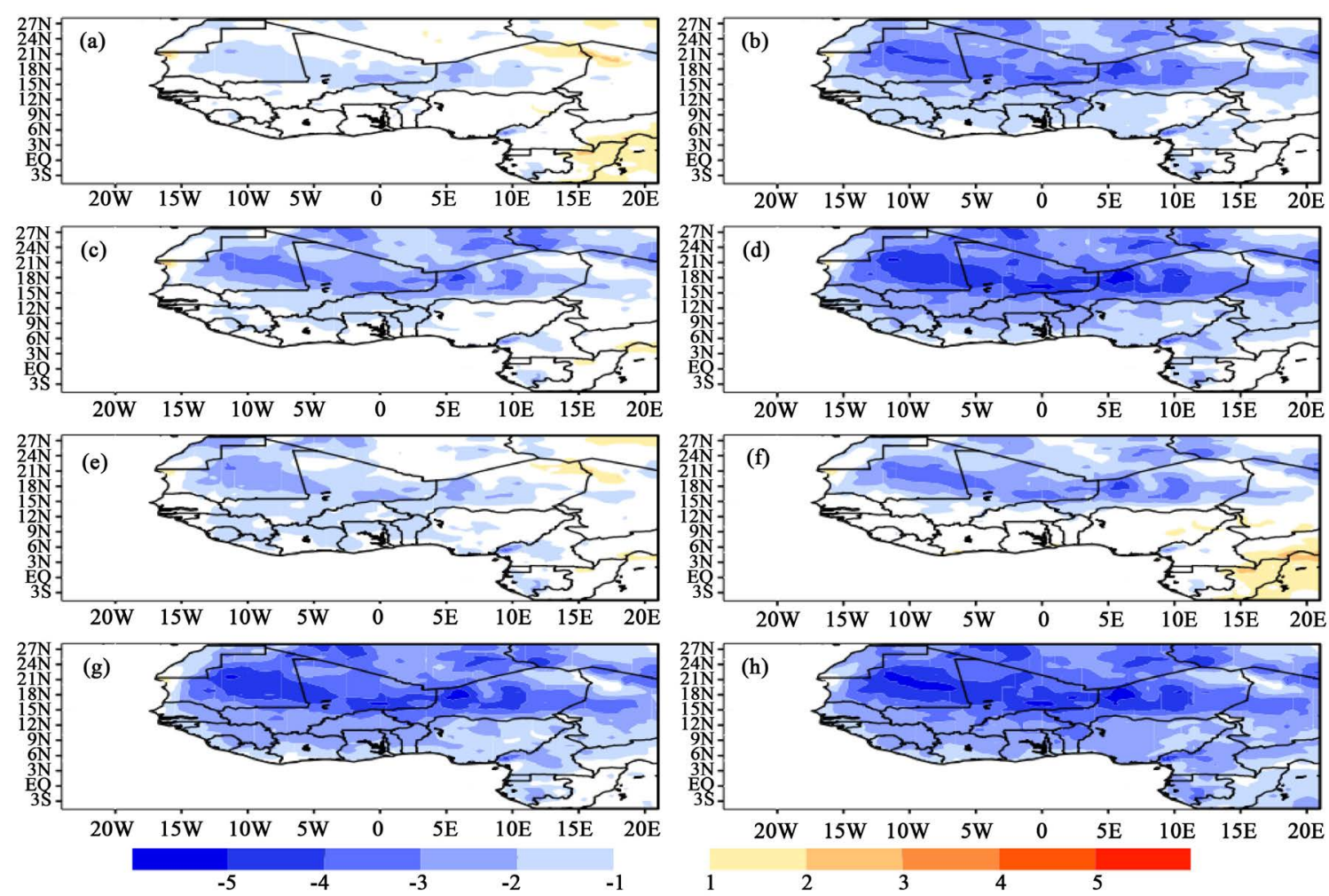

Figure 5. Same as Figure 4 but for mean temperature.

lowest bias compared to CRU. For all other models and the MODENS the dominant picture is a strong cold bias tongue lying over Northern Sahel and the Sahara from Mauritania to Niger. ICH, GFDL and ARP respectively (Figure $5(\mathrm{e})$, Figure 5(g) and Figure 5(h)) have the highest bias, locally reaching $4^{\circ} \mathrm{C}$. This area is the ideal growing/developing area of the Sahara heat Low (SHL), a thermal low known to play a key role in the dynamic of the West Africa Monsoon (WAM). A misrepresentation in GCM fields can be among the potential cause of the cold bias. Other reasons like excess cloudiness, aerosols, surface albedo are mentioned in [33] [34].

The models perform better over the Gulf of Guinea region, with biases below $1^{\circ} \mathrm{C}$.

The Taylor Diagrams (Figure 4(b)), only MODENS with a cc of 0.90 outperform ERA (0.83). For other models the correlation coefficients are between 0.74 for GFDL and 0.63 for ARP. The standard deviations for temperature are between 1.8 and 2.5. Maximum and Minimum temperature will be further investigated in the future projections.

To better understand models biases in precipitation, we investigate additional features: the interannual variability and trends, the annual cycle and a key index (onset of rainy season), monitored for sowing activities of many crops in Sahel countries. Therefore, it is essential to know how well the models simulate these strategic parameters and indices important in many agricultural activities in a vulnerable Sahel region characterize by a high variability in rainy seasons. 


\subsection{Interannual Variability and Trend of Precipitation}

The time series (1981-2005) of annual precipitation, averaged over the SEN, SAH and GOG sub-domains, are compared to the validation dataset GPCP. Figure 6 shows the year-to-year variability of precipitation over SEN domain. The GCPC (Figure 6(a)) has a gradual increase in the mean annual intensity of rainfall as show by the linear trend slope. This positive trend is observed in other models except NCC (Figure 6(d)) with a slightly negative trend. This is consistent with what is observed since the mid-90s after the long drought. This relative recovery is found in many studies and discussed in [26].

The signal is admitted but the major controversy remains on the causes [26]. We use the coefficient of variation (Table 2) for insight on the relative variability of rainfall.
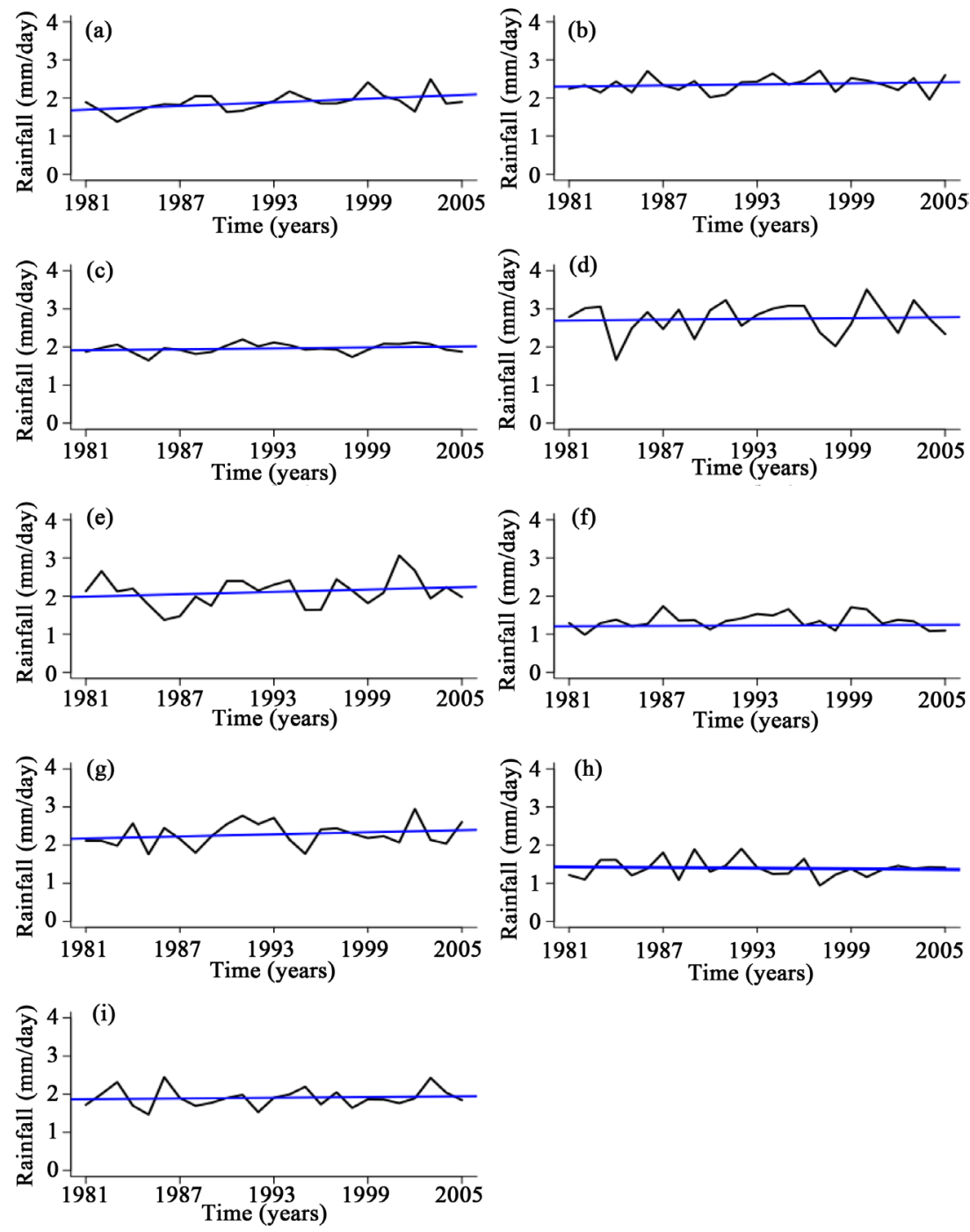

Figure 6. Interannual variability of precipitation ( $\mathrm{mm} /$ day) (black line) and linear trend (blueline) over SEN domain for (a) GPCP; (b) ERA; (c) MODENS; (d) NCC; (e) ARP; (f) CCC; (g) MIROC; (h) GFDL; and (i) ICH. 
Table 2. Onset (Julian days) over the 3 sub-domains of West Africa, SEN, SAH and GOG for the recent past (1981-2005), projection for the intermediate term (IT) (2031-2055) and the fat term (2071-2095) for GPCP, ERA, MODENS, NCC, ARP, MIROC, GFDL and $\mathrm{ICH}$.

\begin{tabular}{|c|c|c|c|c|c|c|}
\hline \multirow[b]{3}{*}{ GPCP } & \multicolumn{2}{|c|}{ HIS } & \multicolumn{2}{|c|}{ IT } & \multicolumn{2}{|c|}{ FT } \\
\hline & \multicolumn{2}{|c|}{ SEN SAH } & \multicolumn{2}{|c|}{ SEN SAH } & \multicolumn{2}{|c|}{ SEN SAH } \\
\hline & 182 & 194 & & & & \\
\hline ERA & 75 & 75 & & & & \\
\hline MODENS & 92 & 96 & 94 & 108 & 98 & 93 \\
\hline NCC & 112 & 112 & 118 & 118 & 97 & 97 \\
\hline ARP & 101 & 101 & 105 & 105 & 104 & 104 \\
\hline CCC & 84 & 84 & 96 & 96 & 85 & 85 \\
\hline MIROC & 69 & 69 & 92 & 93 & 80 & 85 \\
\hline GFDL & 102 & 102 & 96 & 96 & 94 & 94 \\
\hline ICH & 96 & 179 & 88 & 132 & 95 & 95 \\
\hline
\end{tabular}

For the SEN domain, GPCP has a cv of 13.02 almost identical for ARP and MIROC. ICH has a slightly higher interannual variability. The validation model ERA and MODENS mostly have a lower variability corroborated by Figure 6(b) and Figure 6(c). Overall, models perform relatively well in reproducing the observed trend and variability over the SEN domain with a mean rainfall around 2 $\mathrm{mm} /$ day.

Over SAH domain (Figures 7(a)-(i)) the same positive trend as in SEN is observed for GPCP (Figure 7(a)). Except GFDL, ICH and ARP with slightly negative trend, the others models (ERA, NCC, CCC, MIROC and MODENS) simulate the positive trend. ICH, MODENS and ERA have a lower relative interannual variability compared to GPCP and others models which are close (Table 2). Models behavior over SEN and SAH are almost similar and this is realistic because they belong to the long Sahelian band.

Over GOG (Figures 8(a)-(i)) significant differences are observed in terms of mean rainfall, variability and trend. Then mean daily amount in GPCP (Figure $8(\mathrm{a})$ ) is between 4 and $4.2 \mathrm{~mm} /$ day around the end of period. ERA (Figure 8(b)) underestimate the amount but simulates the slight positive trend. NCC and MODENS (Figure $8(\mathrm{~d}$ ) and Figure $8(\mathrm{c})$ ) reproduce fairly well the intensity. The difference in variability between GOG and SAH/SEN is shown in the coefficient of variations (Table 2). GFDL and MIROC (Figure 8(g) and Figure 8(h)) have opposite trend but all overestimate the mean daily rainfall and have the highest relative variability.

The minima, coinciding with the extreme dryness during the Sahel drought $(\mathrm{Lu}, 2009)$ in the early 1980s, are not well captured by only GFDL and MIROC. The other interesting point is the fact that the majority of models are able to capture trends reasonably well but a few of them fail to reproduce the interan- 

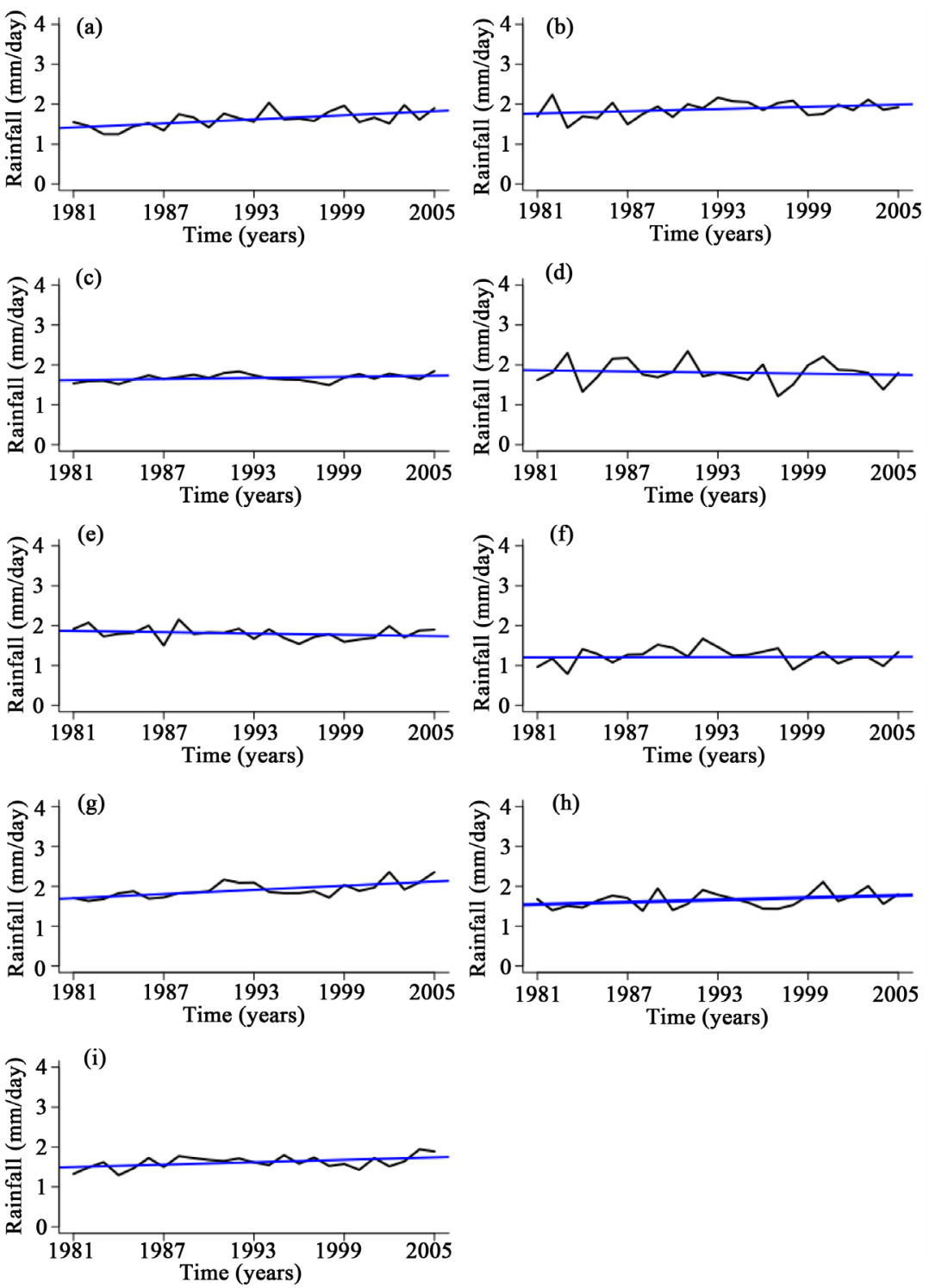

Figure 7. Same as Figure 6 but for SAH domain.

nual variability controlled and modulated by local and remote factors cited in many studies [34] [35] [36].

Meanwhile, we had to consider the fact the model is not driven by observed SST, one of the key modulators of interannual variability of rainfall. The same behavior has been found in other studies using other RCMs [37]. We thus had to take this into account when analyzing the projected interannual variability.

As mentioned above, the CORDEX-Africa domain is not specific for West Africa and many processes are not taken into account by the models (both GCMs and the RCM). The relatively good performance of RCA, on reproducing the mean climate, could be improved by using a tailored domain design for West Africa an taking into account other processes (aerosols, land use etc.) which are fundamental for regional climate modeling [38] [39]. 

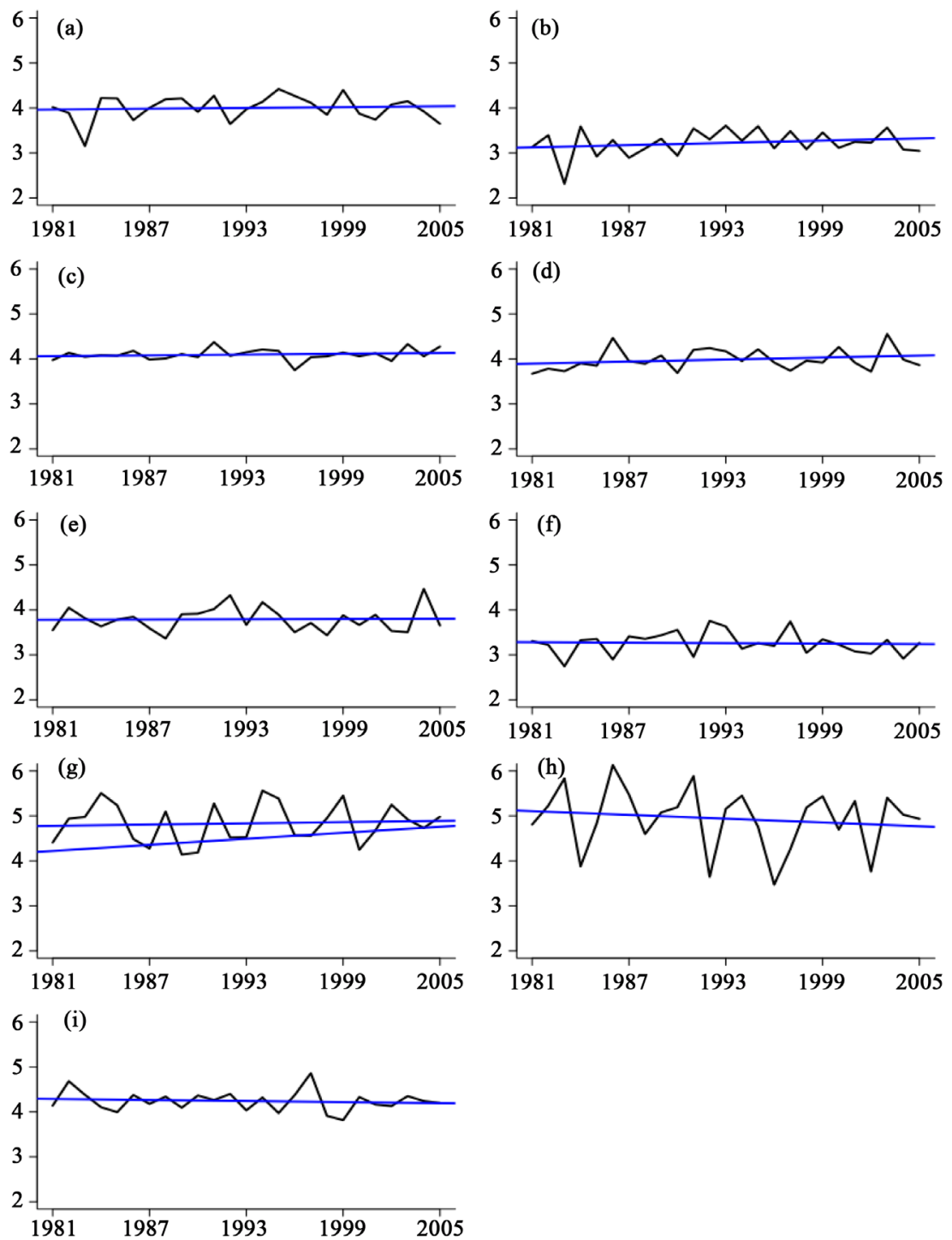

Figure 8. Same as Figure 6 but for GOG domain.

For further insight into the performance of the models in reproducing of the structural behavior of rainfall, it is important to look at annual cycle, which reflect both the northward and withdrawal phases of the ITCZ, a key feature of the West Africa Monsoon (WAM) climate.

\subsection{Seasonal Cycle and Onset}

\subsubsection{Seasonal Cycle}

Over West Africa, from the Gulf of Guinea to the Sahel, the Inter Tropical Convergence Zone (ITCZ) is the dominant feature by characterizing the rainy seasons and has three main phases. It is highly important that models show reasonable potential in simulating these main phases of the ITCZ. A time-latitude diagram is used to represent the annual cycle of precipitation averaged between $10^{\circ} \mathrm{W}$ and $10^{\circ} \mathrm{E}$ (Figures $9(\mathrm{a})$-(i)). We use 5 days running mean on daily preci- 


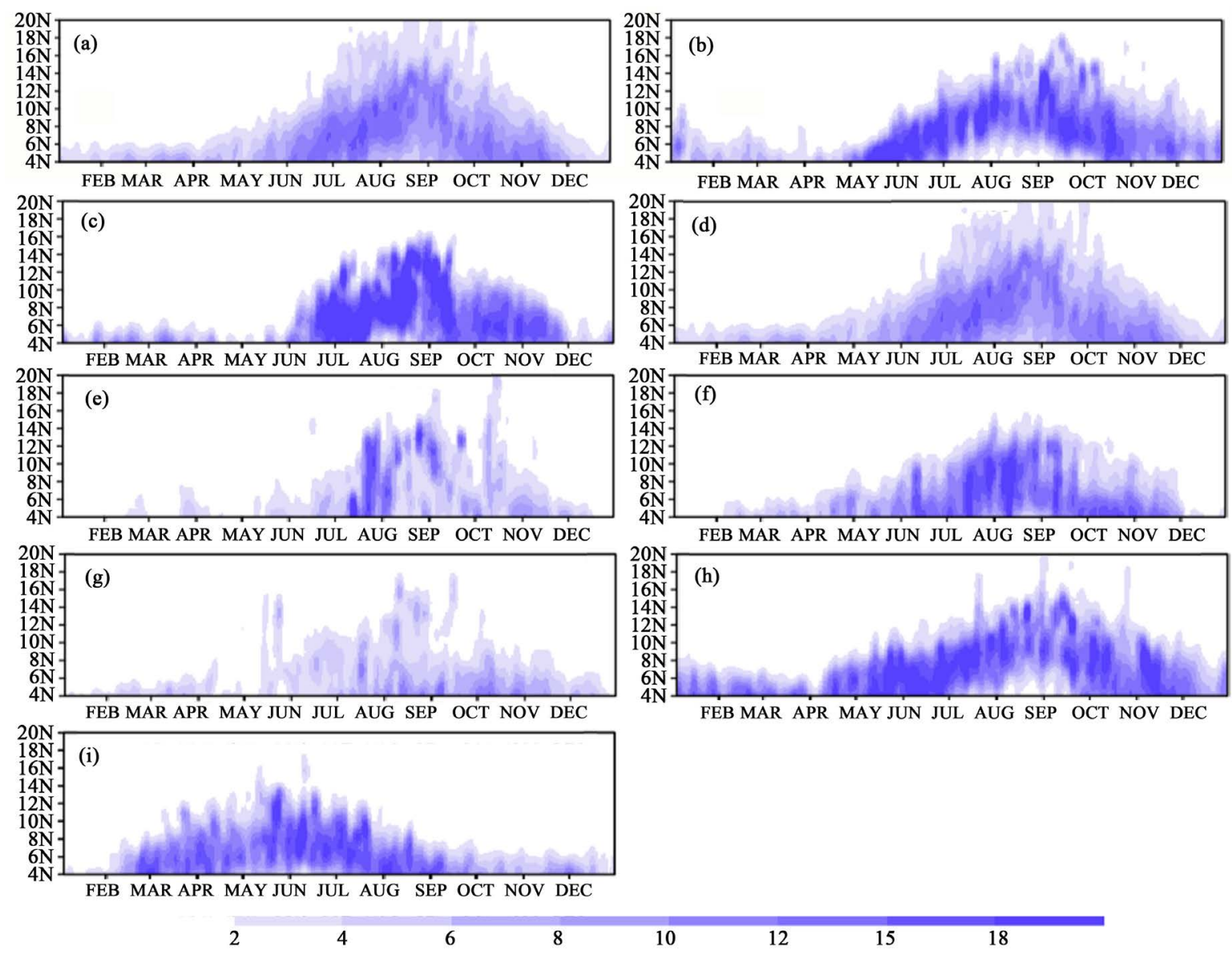

Figure 9. Hovmöller (time/latitude) diagram using a 5 days running mean of daily precipitation (mm/day) (1998-2005) over the West Africa domain representing the northward and withdrawal phases of the Inter-Tropical Convergence Zone (ITCZ) for the validation dataset (a) (GPCP); (b) ERA; (c) MODENS; (d) NCC; (e) ARP; (f) CCC; (g) MIROC; (h) GFDL; and (i) ICH.

pitation to represent the seasonal cycle. The first attention is paid to the one peak regime over Sahel above $10^{\circ} \mathrm{N}$ from mid-June and reaching its maximum on $\mathrm{Au}$ gust followed by a retreat phase, gradually from mid-September to end of October. The GOG with a longer rainfall cycle is known to have a "little dry season" (LDS) from mid-July to mi-September linked to the SST anomalies over the Gulf of Guinea [40], and is better represented using daily data. As opposed to Sahel, over GOG countries rainfall regime is almost continuous throughout the year as sown in Figure 9(a). The wet bias noted over GOG can partially be explained by the weak representation of the LDS by ICH, CCC and ARP (Figure 9(i), Figure 9(f) and Figure 9(e)). One other plausible reason is a behavior known on many GCMs not propagating further north the rain band associate with the ITCZ. ERA, MODENS, MIROC and GFD (Figure $9(\mathrm{~b})$ ), Figure $9(\mathrm{c})$, Figure $9(\mathrm{~g})$ and Figure $9(\mathrm{~h})$ ) simulate the LDS but exhibit differences in the extent, magnitude and timing.

The other dominant feature over the Sahel is the so-called monsoon jump dominantly occurs in the second fortnight of June [15] [24] [41] [42]. Looking at Figure 9(a), the monsoon jump in GPCP occurs on average in the $3^{\text {rd }}$ decade of 
June. This consistent with what is found in [24] where they inter-compared different observed dataset and different version of a regional climate model. The verification model ERA (Figure 9(b)), realistically reproduce the phases of the seasonal cycle over both SAH and GOG. MODENS and MIROC show skills in reproducing realistic seasonal cycle.

\subsubsection{Onset}

Another key indicator for agriculture is the onset of rainy season, mainly valid over the Sahel. It is defined as the first three consecutive days of rainfall, reaching at least $20 \mathrm{~mm}$ and that is not followed by 10 consecutive days without rain in the month [25]. This definition is the standard applied by AGRHYMET and recommended to all Sahelian countries that are members of CILSS. Following the annual cycle presented above, the onset of the monsoon season over the Sahel generally occurs gradually from June to July and corresponds to the sowing period for the major rainfed crops. A false start of the rainy season could lead to re-sowing and other implications that affect later crop maturity [43]. Figures 10(a)-(i)) represents the onset of the rainy season over the Sahel band (in Julian days) for the validation dataset GPCP (Figure 10(a)), the verification model ERA (Figure 10(b)), the other runs from GCMs and their ensemble show a noticeable lack of skill in certain models in reproducing the onset of rainy season
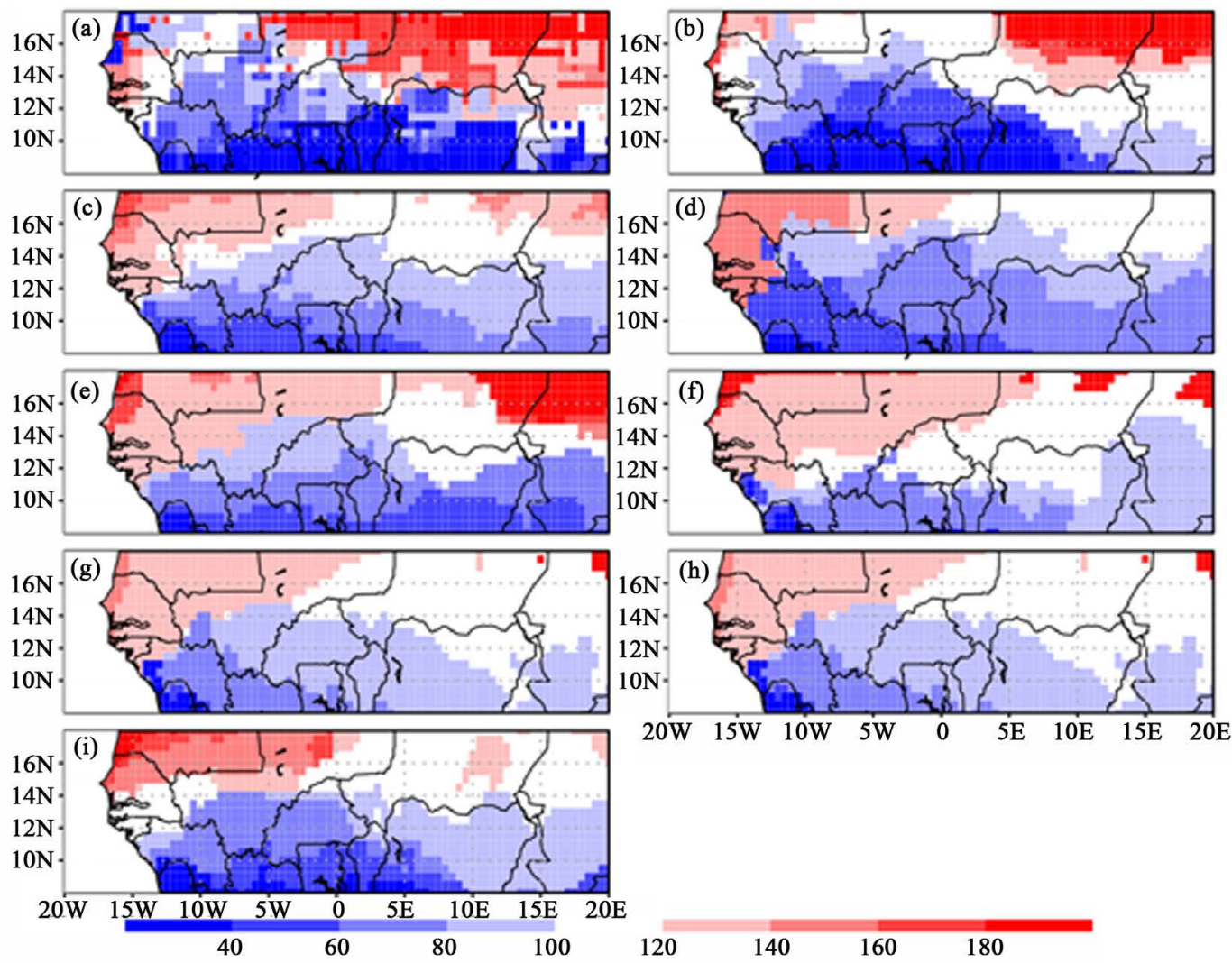

Figure 10. Spatial representation of the onset (in Julian days) over West Africa, with a special focus on the Sahel for the validation dataset (a) (GPCP); (b) ERA; (c) MODENS; (d) NCC; (e) ARP; (f) CCC; (g) MIROC; (h) GFDL; and (i) ICH. 
over Sahel in general and in individual sub-domains SEN, SAH and GOG (summarized in Table 3). Failing to reproduce the seasonal cycle will unequivocally lead to a failure in simulating the onset of the rainy season. GPCP (Figure 10(a)) the onset criteria are meet between Julian day 100 (mid-April) and 180 (end-June).

Over SEN a blue band is noticed over the northwest, meaning an early onset. This is realistic and certainly link to off-season rains known to occur from Cape Verde to Senegal and Mauritania where they are observed between November and March ([44] [45]). Over Niger and northern Mali, the onset window is between Julian day 120 and 180. Only a few models have a realistic onset. ARP, CCC and GFDL have an onset window between 100 and 160 on eastern parts of the domain and between 120 and 140 toward western Senegal/south Mauritania. Table 3 shows that ERA, CCC and MIROC with respectively 75, 84 and 69 don't have a significant skill in representing the maximum onset compared to GPCP. This is certainly due to the complexity of the onset criteria for GCMs and RCMs simulation as they induce more light rains than observed and shown in many studies [16] [24] [27].

\section{Projections under RCP8.5}

\subsection{Precipitation and Temperature Projected Change}

\subsubsection{Precipitation}

Based on the historical reference period analysis, we explore the projected climate change under RCP8.5 over West Africa and the selected sub-domain for an intermediate term (IT) 2031-2055 and a far term (FT) 2071-2095.

For precipitation, slightly wetter conditions are projected for the IT over the Gulf of Guinea countries (Example of NCC (Figure 11(b)) and MIROC (Figure $11(\mathrm{e})$ ). No change to little increase is projected by ICH (Figure 11(g)), GFDL

Table 3. Coefficient of Variation (CV) (\%) for annual precipitation averaged over 3 subdomains for the recent past (1981-2005), projection for the intermediate term (IT) (20312055) and the far term (FT) (2071-2095) for GPCP, ERA, MODENS, NCC, ARP, CCC, MIROC, GFDL and I CH.

\begin{tabular}{ccccccccccc}
\hline Periods & \multicolumn{3}{c}{ HIS $(1981-2005)$} & \multicolumn{2}{c}{ IT (2031-2055) } & \multicolumn{2}{c}{ FT (2071-2095) } \\
\hline Domains Data & \multicolumn{3}{c}{ SEN SAH GOG } & \multicolumn{2}{c}{ SEN SAH GOG } & \multicolumn{2}{c}{ SEN SAH GOG } \\
\hline GPCP & 13.02 & 12.98 & 7.02 & & & & & & \\
ERA & 8.72 & 11.10 & 9.03 & & & & & & \\
MODENS & 15.85 & 11.59 & 9.08 & 16.15 & 12.71 & 8.09 & 14.96 & 13.87 & 9.22 \\
NCC & 17.50 & 11.99 & 5.89 & 20.59 & 21.24 & 12.95 & 16.47 & 13.61 & 8.17 \\
ARP & 13.05 & 9.77 & 7.17 & 17.15 & 9.54 & 10.40 & 13.44 & 7.48 & 5.27 \\
GPCP & 14.81 & 16.44 & 7.79 & 20.04 & 9.01 & 6.70 & 16.16 & 11.46 & 9.75 \\
MIROC & 13.72 & 10.22 & 9.02 & 13.05 & 11.97 & 8.08 & 14.49 & 10.54 & 6.12 \\
GFDL & 15.47 & 15.93 & 14.06 & 15.78 & 13.08 & 7.87 & 16.76 & 29.12 & 10.44 \\
ICH & 18.68 & 8.90 & 5.38 & 13.14 & 12.70 & 5.54 & 13.36 & 11.42 & 6.28 \\
\hline
\end{tabular}





Figure 11. Projected change in precipitation ( $\mathrm{mm}$ /day) by RCA as a response to GHG emissions under RCP8.5 for the intermediate term (IT) (2031-2055) over West Africa domain for the different forcing GCMs and their ensemble: (a) MODENS; (b) NCC; (c) ARP; (d) CCC; (e) MIROC; (f) GFDL; and (g) ICH.

(Figure 11(f)), MODENS (Figure 11(a)) and ARP (Figure 11(c)). Over Senegal, MIROC and CCC project dryer conditions, stronger in MIROC with a decrease reaching $1.6 \mathrm{~mm} /$ day over southern Senegal. This feature has been emphasized in IPCC reports AR4 and AR5. The other models don't exhibit significant change for the IT.

For FT (Figures 12(a)-(g)), an amplification of wetter conditions is projected over the Guinea coast countries. The increase is extended in large parts of Sahel. The major noticeable difference is over Senegal where dryer conditions remain. This clearly looks like a consistent and strong signal reported since AR4. Only NCC (Figure 12(b)) is projecting an opposite sign over Senegal.

\subsubsection{Temperature}

Concerning temperature, our attention is paid on the change in extremes (minimum and maximum). The general picture is the warming projected over the whole domain for both the IT and the FT. The warming magnitude for minimum temperature (Figures $13(\mathrm{a})-(\mathrm{g}))$ is generally between $1.5^{\circ} \mathrm{C}$ and $3^{\circ} \mathrm{C}$ reaching more than $6^{\circ} \mathrm{C}$ in CCC (Figure 13(d)).

An identical picture with an amplification of the warming is projected for the FT. It reaches between $3^{\circ} \mathrm{C}$ and $6^{\circ} \mathrm{C}$ with local maxima of more than $6^{\circ} \mathrm{C}$ for 



$\begin{array}{llllllll}0.4 & 0.6 & 0.8 & 1 & 1.2 & 1.4 & 1.6 & 1.8\end{array}$

Figure 12. Same as Figure 11 but for FAR TERM (FT) 2071-2095.
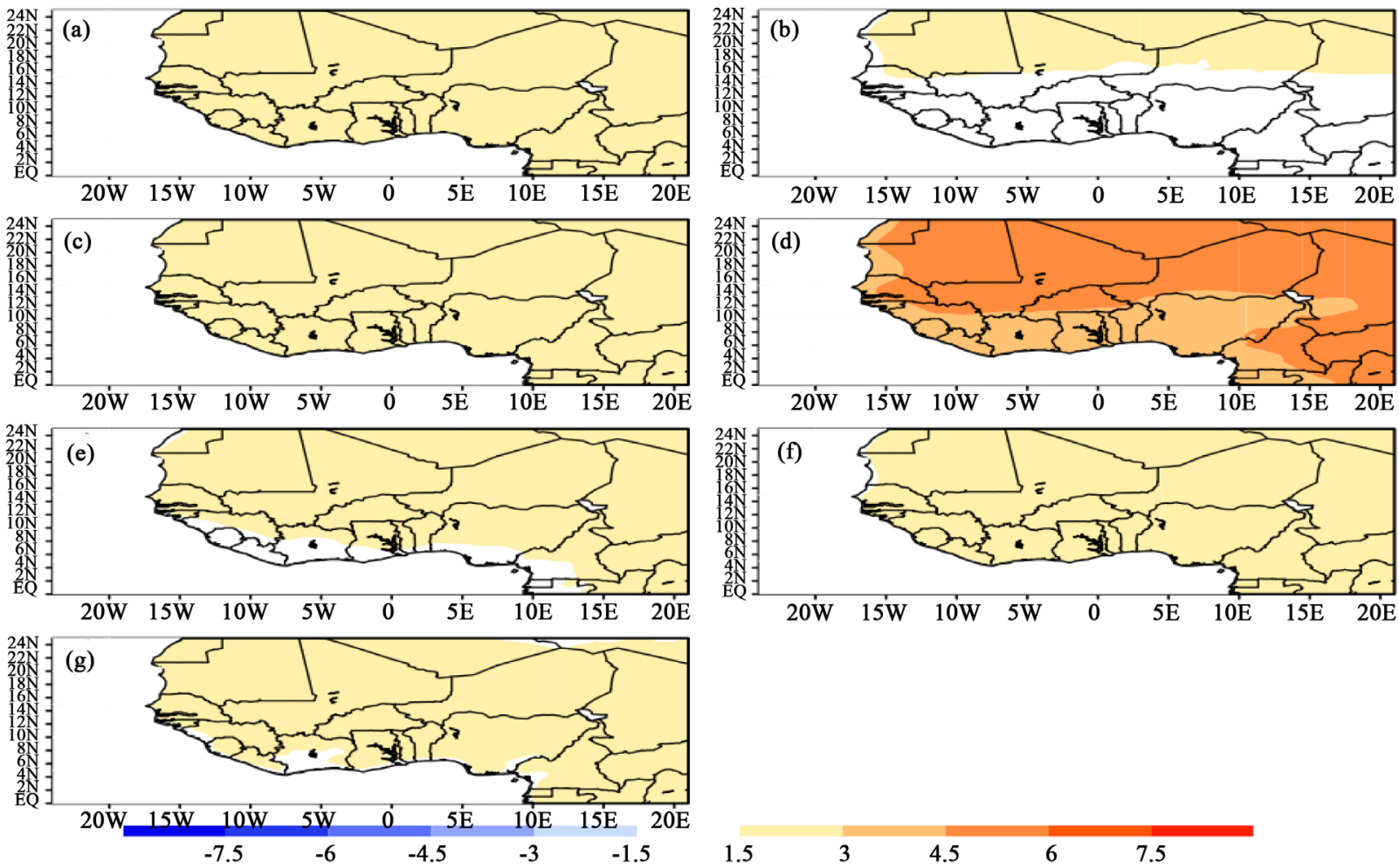

$\begin{array}{lllll}1.5 & 3 & 4.5 & 6 & 7.5\end{array}$

Figure 13. Projected change in maximum temperature $\left({ }^{\circ} \mathrm{C}\right)$ by RCA as a response to GHG emissions under RCP8.5 for the intermediate term (IT) (2031-2055) over West Africa domain for the different forcing GCMs and their ensemble: (a) MODENS; (b) NCC; (c) ARP; (d) CCC; (e) MIROC; (f) GFDL; and (g) ICH. 


\section{CCC (Figure 14(d)).}

A noticeable feature is the fact that the warming projected between IT and FT in minimum temperature is stronger than in maximum temperature. For the IT (Figure 15) the warming is between $1.5^{\circ} \mathrm{C}$ and $3^{\circ} \mathrm{C}$ for almost all models except CCC where it is between $4.5^{\circ} \mathrm{C}$ and $6^{\circ} \mathrm{C}$, over the Sahara and northern Sahel. For the FT (Figure 16), the warming is mainly between 3 and 4.5 except CCC projecting slightly warmer condition. This result is also consistent with what was found in AR4 and AR5 reports.

\subsection{Seasonal Cycle and Onset}

With weak performance of the models in simulation reasonably well the seasonal cycle reduces the confidence in change seen in both the IT and FT. One clear picture not shown is that the precipitation is not extending further north over the Sahel in almost all models. An apparent shift with a delayed monsoon Jump is projected and an LDS in August is project by ARP. Except over Sahel, the seasonal cycle in MIROC don't show significant changes. For the FT the ITCZ is further south over the northern Sahel.

For the onset of rainfall, the maxima of onset vary in the IT between 93 for MIROC in SEN and SAH and 118 for NCC (Table 3). MODENS projects relatively realistic onset for both IT and FT. For the FT except ARP with a maximum onset of Julian day 104 all other models are bellow day 100. These results don't show a clear picture on a strong signal of early/(delayed) onset or a con-
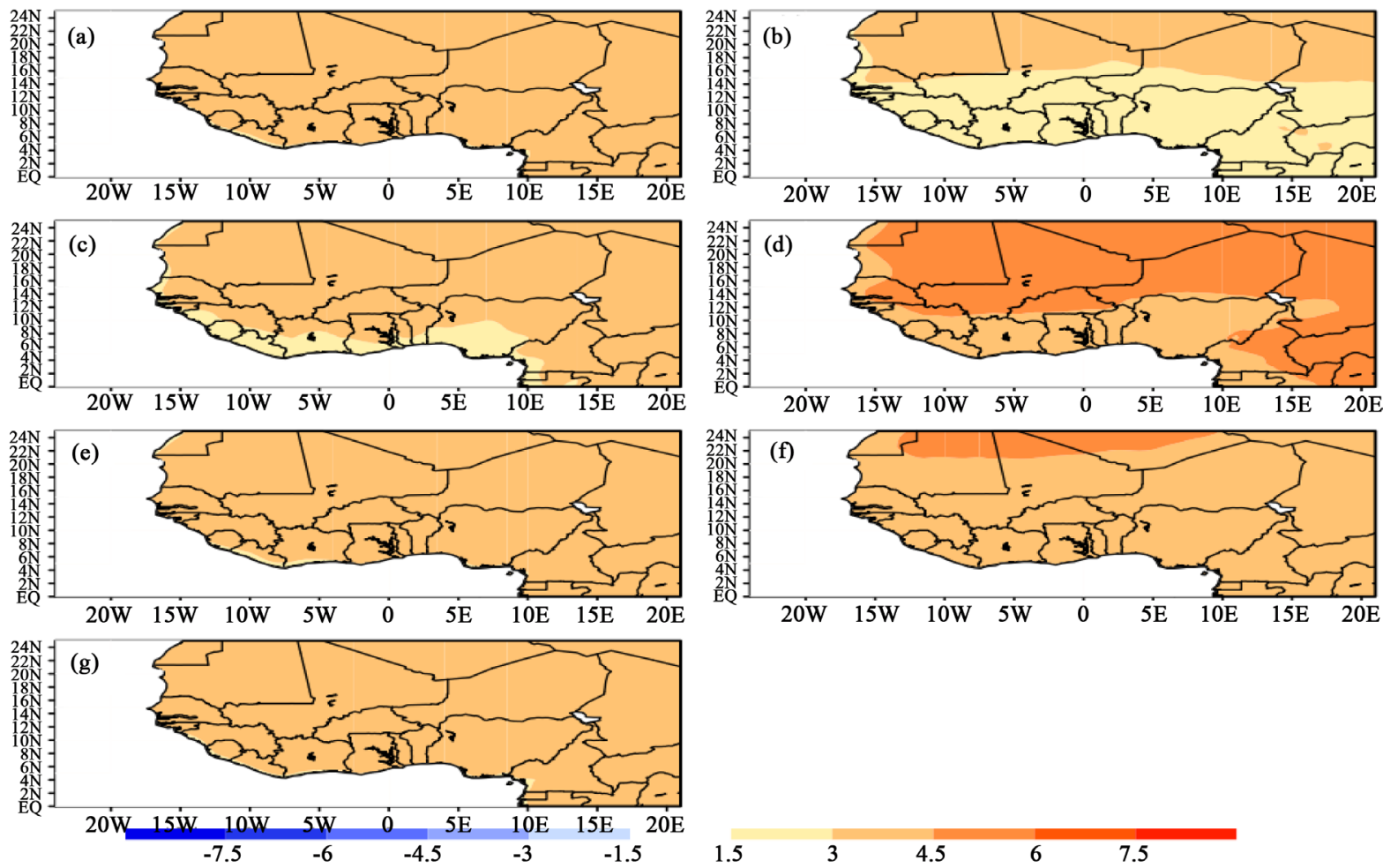

Figure 14. Same as Figure 13 but for FAR TERM (FT) 2071-2095. 

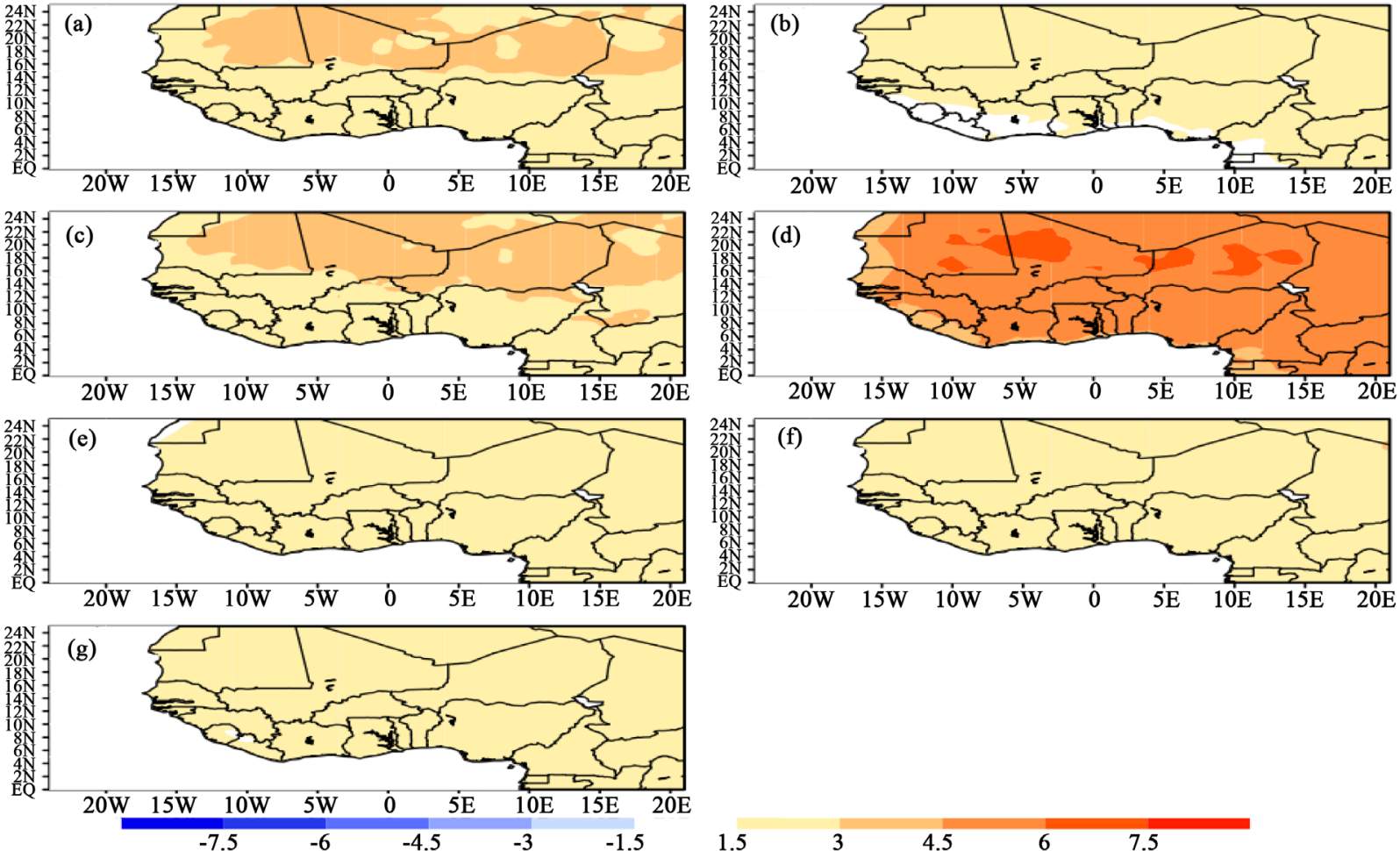

$\begin{array}{lllll}1.5 & 3 & 4.5 & 6 & 7.5\end{array}$

Figure 15. Projected change in minimum temperature $\left({ }^{\circ} \mathrm{C}\right)$ by RCA as a response to GHG emissions under RCP8.5 for the intermediate term (IT) (2031-2055) over West Africa domain for the different forcing GCMs and their ensemble: (a) MODENS; (b) NCC; (c) ARP; (d) CCC; (e) MIROC; (f) GFDL; and (g) ICH.
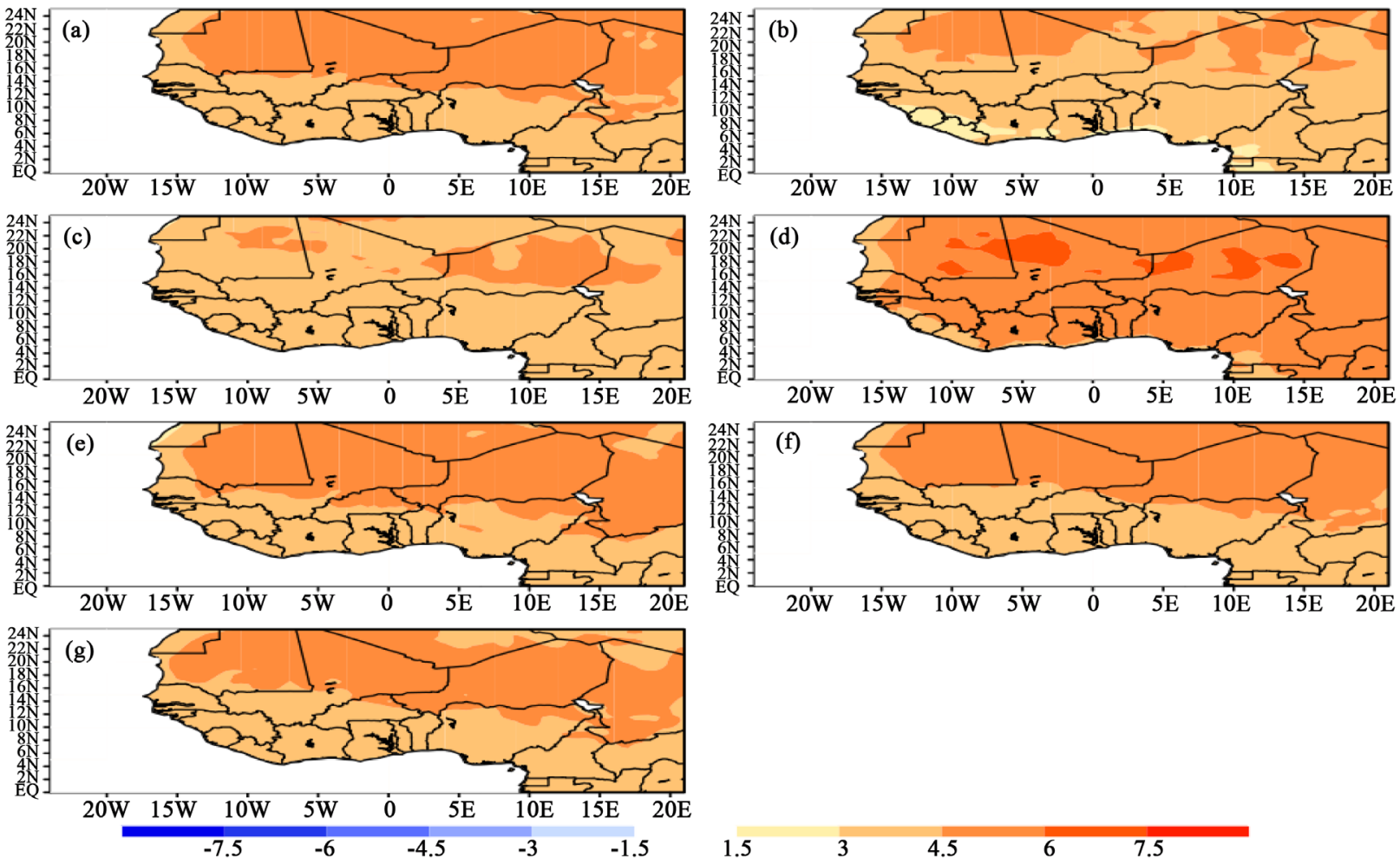

Figure 16. Same as Figure 15, but for the FAR TERM (FT). 
firmation of the failure of models in simulating the onset but also the different phases of the seasonal cycle.

\subsection{Interannual Variability and Trend}

The trend is analyzed over the 3 sub-domains SEN (Figures 17(a)-(g)) and (Figures 18(a)-(g)), SAH (Figures 19(a)-(g)) and (Figures 20(a)-(g)), GOG (Figures 21(a)-(g)) and (Figures 22(a)-(g)).


Figure 17. Projected precipitation interannual variability and trend over SEN domain for the intermediate term (2031-2055) for (a) MODENS; (b) NCC; (c) ARP; (d) CCC; (e) MIROC; (f) GFDL; and (g) ICH. 

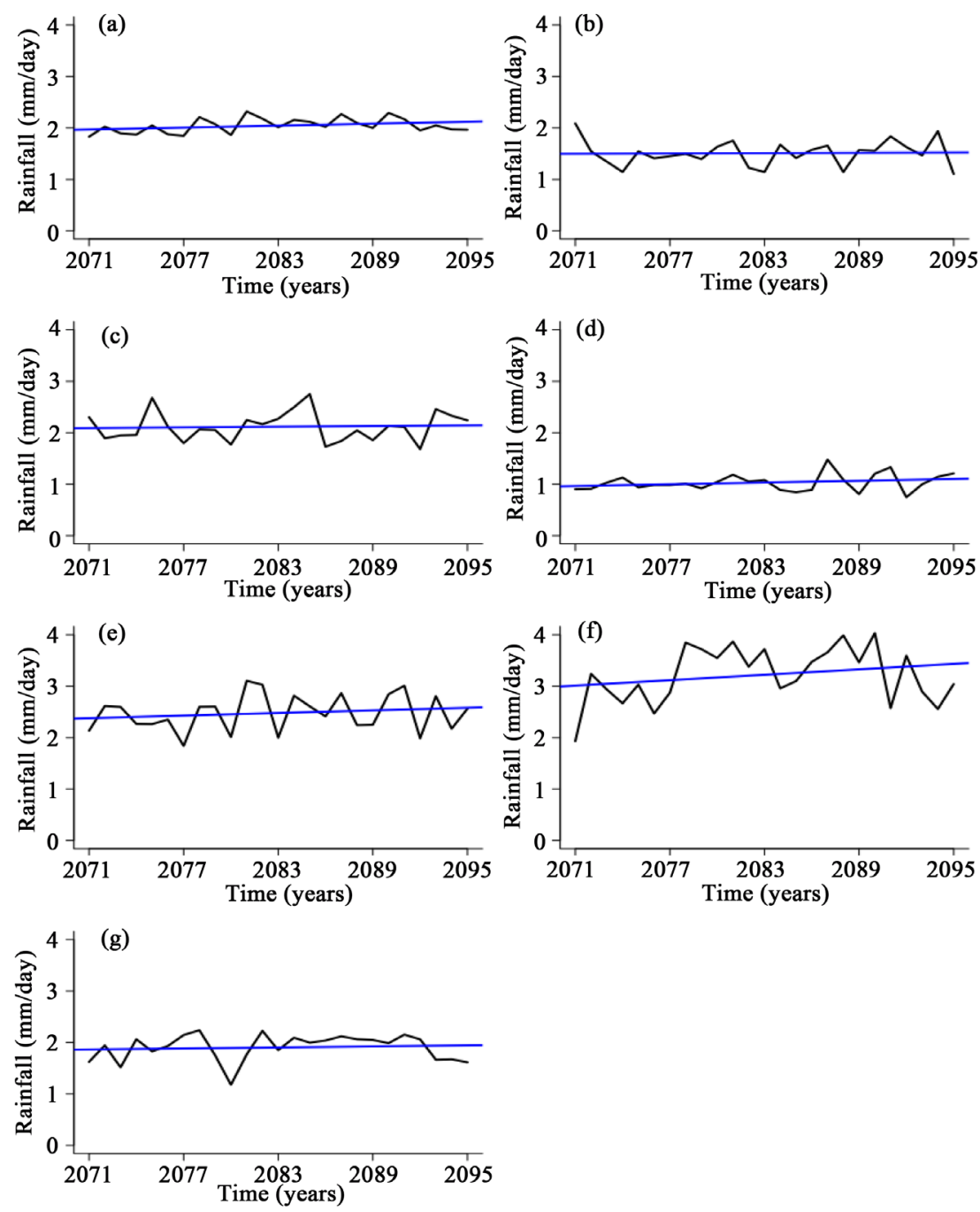

Figure 18. Same as Figure 17 but for FAR TERM (FT) 2071-2095.

\subsubsection{Intermediate Term}

For SEN, only GFDL (Figure 17(f)) is projecting a positive trend with a mean daily rainfall of 2.9 increasing up to $3.2 \mathrm{~mm}$ /day at the end of the period 2055 . The other models project a negative trend or no slope. For NCC and CCC (Figure 17(b) and Figure 17(d)) the mean daily rainfall is around $1.2 \mathrm{~mm} /$ day against $2 \mathrm{~mm}$ /day for ICH, MIROC and MODENS. The relative variability is higher compared to the historical period (Table 2). The highest relative variability is projected in models like NCC and CCC.

For the SAH domain, what is projected is close to what we have on the SEN domain. We have less relative variability in other models except NCC (Figure 19(b)) the highest with a coefficient of variation of $21.24 \%$. GFDL projects a positive trend but a lower mean daily amount compared to SEN.

The lower variability in GOG seen in the historical period is found in the IT. The negative trend is only projected by NCC (Figure 21(d)), which also have the smallest mean rainfall amount around $3.4 \mathrm{~mm} /$ day. The wetter conditions pro- 

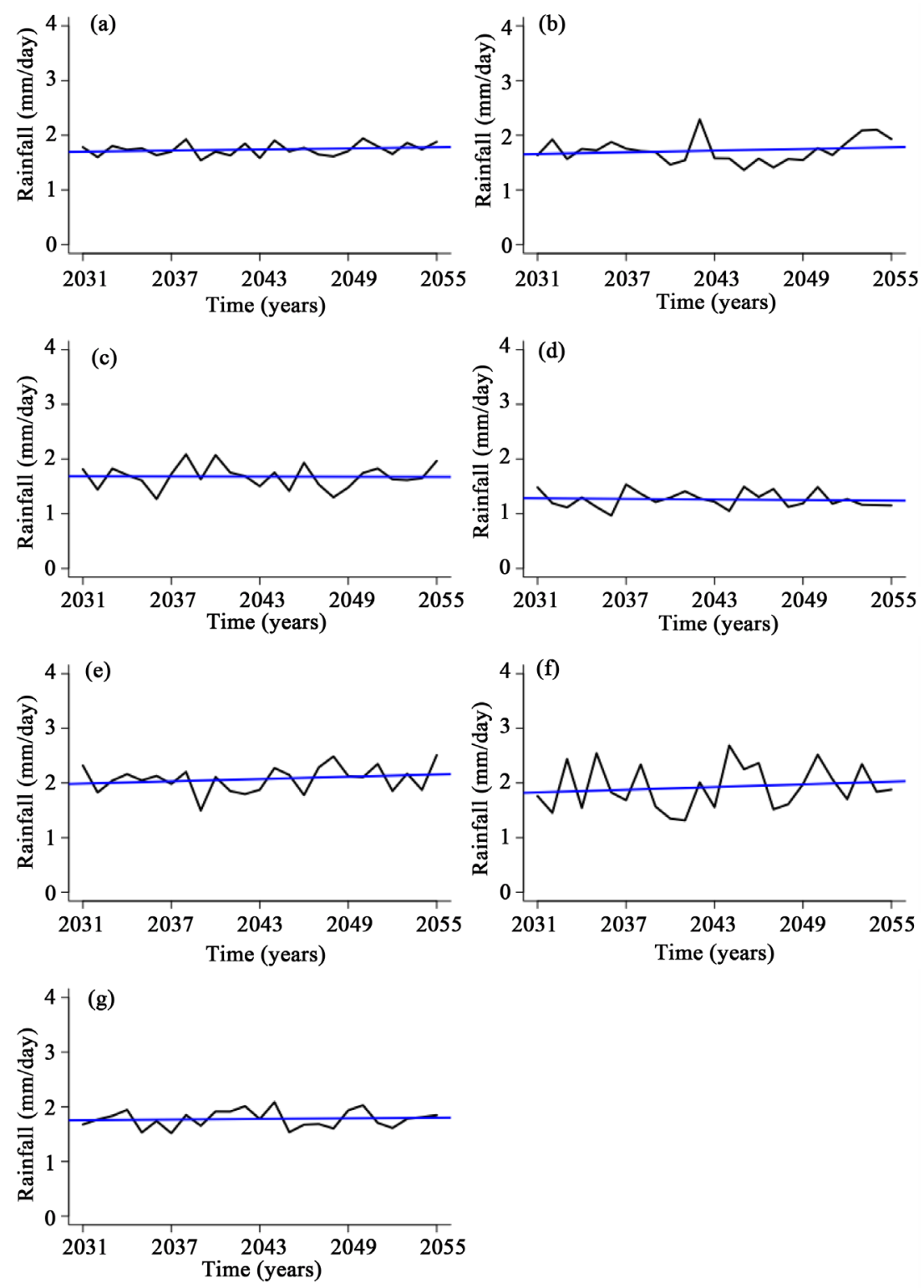

Figure 19. Projected precipitation interannual variability and trend over SAH domain for the intermediate term (2031-2055) for (a) MODENS; (b) NCC; (c) ARP; (d) CCC; (e) MIROC; (f) GFDL; and (g) ICH.

jected in the climatology is reflected in the trend for other models with the mean daily rainfall between 4 and $5.5 \mathrm{~mm}$ /day.

\subsubsection{Far Term}

GFDL and MIROC (Figure 18(f) and Figure 18(e)) have a slightly positive trend and higher mean daily rainfall ( 2.5 to $3 \mathrm{~mm} /$ day) compared to the historical period. For the other models the mean daily rainfall is between $2 \mathrm{~mm} /$ day for MODENS and ICH and 1 and $1.5 \mathrm{~mm} /$ day for ICH and NCC.

For SAH (Figures 20(a)-(g)) a positive trend is projected by almost all models with a mean daily rainfall amount increasing to $2 \mathrm{~mm} /$ day. 



Figure 20. Same as Figure 19 but for FAR TERM (FT) 2071-2095.

The small relative variability mentioned in for the historical and near term periods is also seen in the far term (Table 2). NCC and GFDL have a slightly negative trend and the mean daily rainfall amount vary between $3.5 \mathrm{~mm}$ for CCC (Figure 22(d)) and $5.5 \mathrm{~mm}$ for GFDL (Figure 22(f)).

Giogi and Coppola (2010) found that for precipitation, the projected change is largely independent of the model bias over a given region. They stated that regional model in impact assessment studies need to be conducted carefully, because models with small and large biases can produce substantially different results. This explains our consideration of all projected climates by RCA, driven by different GCMs, in our analysis, while keeping in mind the high level of uncertainty associated with the response of West Africa climate to anthropogenic GHG emissions [46] [47] [50]. 

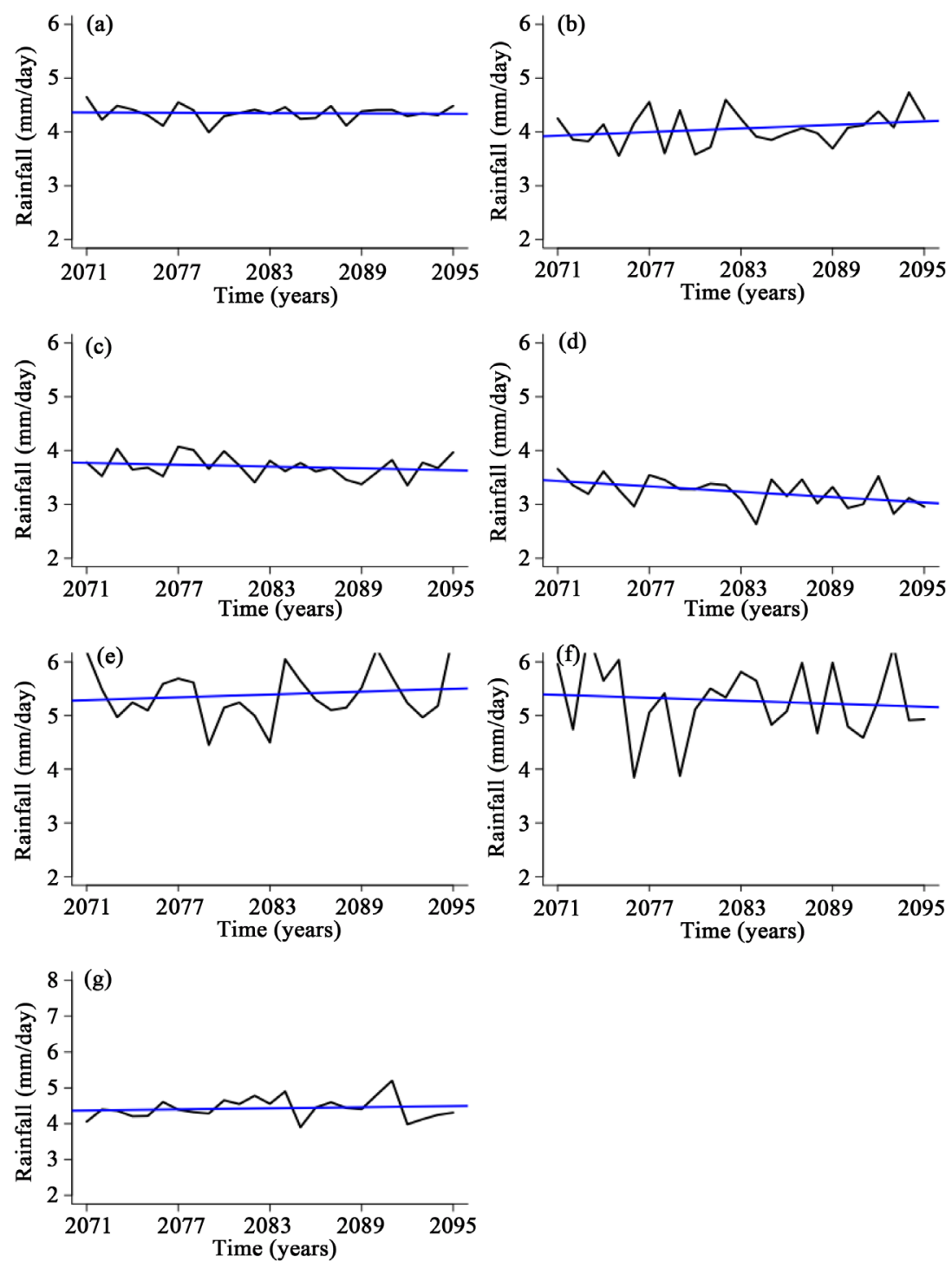

Figure 21. Projected precipitation interannual variability and trend over GOG domain for the intermediate term (2031-2055) for (a) MODENS; (b) NCC; (c) ARP; (d) CCC; (e) MIROC; (f) GFDL; and (g) ICH.

\section{Discussion and Conclusions}

In this paper, we explored simulations with multi-GCMs as boundary and initial conditions, conducted with SMH-RCA version 3.5 model in the framework of CORDEX-AFRICA. Transient runs were carried out from 1951 to 2100, in two phases. These were the historical period up to December 2005 and projection for the period 2006-2100 using RCP8.5. Our main focus is West Africa and 3 homogenous sub-regions, the Sahel region (SAH), a western domain SenegalGambia (SEN) and the Gulf of Guinea (GOG). The RCA model in these experiments was forced by a verification model ERA-Interim (ERA) for the period 1979 to 2005) and 6 GCMs (NCC, ARP, CCC, MIROC, GFDL, ICH and their ensemble MODENS). 

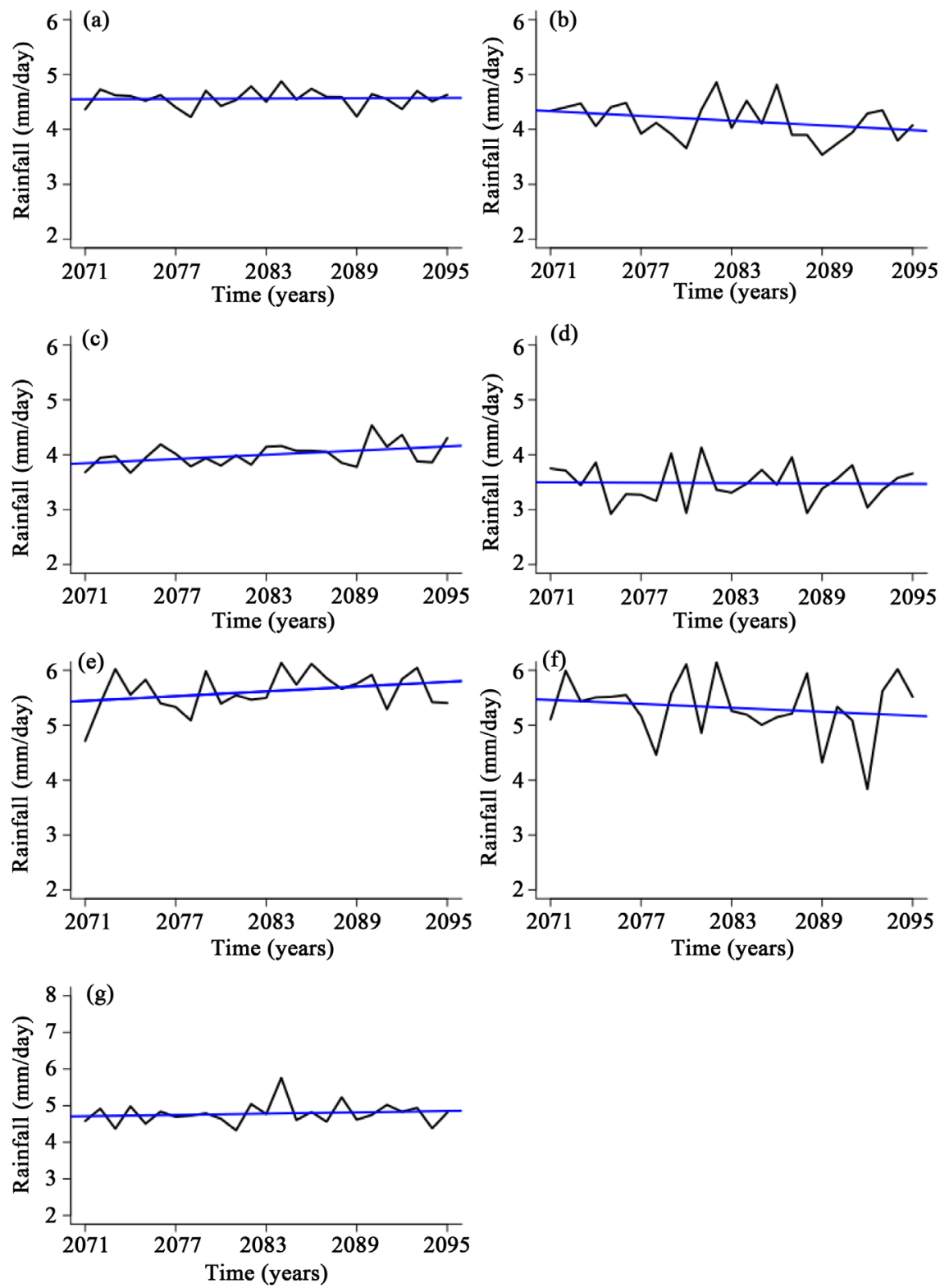

Figure 22. Same as Figure 21 but for FAR TERM (FT) 2071-2095.

Our study results on the investigation of simulated precipitation and temperature have shown a qualitative improvement in the simulation of the spatial patterns of parameters like precipitation. We found that for both parameters (precipitation and temperature), MODENS always exhibits the highest correlation which reaches (0.96) for precipitation. The fact that MODENS outperforms individual GCMs and the verification model has been found in multi-RCMs simulation [15]. These results indicate that the ensemble can be a good strategy for modeling strategy and should be given a high weight. Further studies are still needed using others models to determine the growing interest in added value brought by ensemble. 
It also appears from our study that a few GCMs outperform the verification simulation ERA, demonstrating the net improvement mentioned and the added value brought internally by the RCM. Except NCC, the other models and the ensemble were able to capture reasonably the relative positive trend in precipitation over SEN and SAH domains in the historical period. A basic difference between models was on the scale of relative variability expressed by the coefficient of variation. The seasonal cycle and the known monsoon Jump [36] was relatively well simulated by only the verification model ERA, MODENS and ICH. Models also failed to simulate the onset of the rainy season also seen in other studies using other RCMs (e.g. [24]), and mainly an early onset is simulated by models. Results have shown that RCA, when forced by realistic boundaries, can reproduce the annual cycle of precipitation over West Africa reasonably well. Further, the little dry season (LDS) over central Gulf of Guinea is well reproduced by a significant number of models. The weak representation of the annual cycle of precipitation is very likely induced by the GCMs and is the cause of the shortcomings in models like ICH, CCC, ARP and CCC. Representation of the onset of the rainy season is thus poorly captured by most models while only marginal accuracy is attained below $14^{\circ} \mathrm{N}$. Indeed, most models failed to reproduce the onset of the rainy season or deviated from the real picture by showing it as too early.

About temperature, it is important to highlight the systematic cold bias, in most models, observed over the Sahara, around the ideal growing/developing area of the Sahara Heat Low (SHL). This is a key feature during the monsoon season and shown in previous studies [15]. Relative to extremes (minimum and maximum temperature), a strong warming signal is projected for both the near and far terms by all models but with difference in magnitude. This will very likely induce negative impacts on agriculture [48]. Another finding of the study is the fact that warming between $\mathrm{NT}$ and $\mathrm{FT}$ is higher in minimum temperature compared to maximum temperature.

Under RCP8.5 a slight increase is projected in precipitation in many parts of West Africa, mainly over the Gulf of Guinea and eastern Sahel. Over the Western Sahel centered on SEN domain, a net decrease and/or no significant change in precipitation, is projected by the majority of models except mainly NCC. This result has been found and expressed in both AR4 and AR5 [8] [49]. This could make this part of Sahel a "hot spot" region requiring further investigation in order to better quantify the magnitude of the change but also major drivers in terms of circulation which is outside the scope of this paper. The increase in projected rainfall, weak in the near term is significant in the far term over Eastern Sahel and Gulf of Guinea regions. Trends mainly exhibit a slightly negative slope in the near term and a relatively positive slope in the far term by a few models and MODENS. On both domains SEN, SAH and GOG MODENS project a positive trend for the FT and almost a constant trend for the NT. 


\section{Acknowledgements}

The authors wish to extend their appreciation to the Swedish Meteorological and Hydrological Institute for providing the simulations and would like to acknowledge CRU, GPCP for providing the observation dataset. We also thank the anonymous reviewers with their valuable comments that helped improve the paper.

\section{References}

[1] IPCC Climate Change (2007) The Physical Science Basis. Contribution of Working Group I to the Fourth Assessment Report of the Intergovernmental Panel on Climate Change. Solomon, S., Qin, D., Manning, M., Chen, Z., Marquis, M., Averyt, K.B., Tignor, M. and Miller, H.L., Eds., Cambridge University Press, Cambridge and New York, 996 pp.

[2] IPCC Climate Change (2013) The Physical Science Basis. Contribution of Working Group I to the Fifth Assessment Report of the Intergovernmental Panel on Climate Change. Stocker, T.F., Qin, D., Plattner, G.-K., Tignor, M., Allen, S.K., Boschung, J., Nauels, A., Xia, Y., Bex, V. and Midgley, P.M., Eds., Cambridge University Press, Cambridge, and New York, 953-1028.

[3] Nicholson, S.E. (2001) Climatic and Environmental Change in Africa during the Last Two Centuries. Climate Research, 17, 123-144.

https://doi.org/10.3354/cr017123

[4] Jenkins, G.S., Gaye, A.T. and Sylla, B. (2005) Late 20th Century Attribution of Drying Trends in the Sahel from the Regional Climate Model (RegCM3). Geophysical Research Letters, 32, Article ID: L22705. https://doi.org/10.1029/2005GL024225

[5] Moufouma-Okia, W. and Rowell, D. (2010) Impact of Soil Moisture Initialisation and Lateral Boundary Conditions on Regional Climate Model Simulations of the West African Monsoon. Climate Dynamics, 35, 213-229. https://doi.org/10.1007/s00382-009-0638-0

[6] Sylla, M.B., Gaye, A.T., Pal, J.S., Jenkins, G.S. and Bi, X.Q. (2009) High Resolution Simulations of West Africa Climate Using Regional Climate Model (RegCM3) with Different Lateral Boundary Conditions. Theoretical and Applied Climatology, 98, 293-314. https://doi.org/10.1007/s00704-009-0110-4

[7] Christensen, J.H, Hewitson, B., Busuioc, A., Chen, A., Gao, X., Held, I., Jones, R., Kolli, R.K., Kwon, W.-T., Laprise, R., Magaña Rueda, V., Learbsn, L., Menéndez, C.G., Räisänen, J., Rinke, A., Sarr, A. and Whetton, P. (2007) Regional Climate Projections. In: Solomon, S., Qin, D., Manning, M., Chen, Z., Marquis, M., Averyt, K.B., Tignor, M. and Miller, H.L., Eds., Climate Change 2007: The Physical Science Basis. Contribution of Working Group I to the Fourth Assessment Report of the Intergovernmental Panel on Climate Change, Cambridge University Press, Cambridge and New York, 848-940.

[8] Druyan, L.M., Feng, J.M., Cook, K.H., Xue, Y.K., Fulakeza, M., Hagos, S.M., Konare, A., Moufouma Okia, W., Rowell, D.P., Vizy, E.K. and Ibrah, S.S. (2010) The WAMME Regional Model Intercomparisonstudy. Climate Dynamics, 35, 175-192. https://doi.org/10.1007/s00382-009-0676-7

[9] Xue, Y., De Sales, F., Lau, W.M., Boone, A., Feng, J., Dirmeyer, P. and Wu, M.L.C. (2010) Intercomparison and Analyses of the Climatology of the West African Monsoon in the West African Monsoon Modeling and Evaluation Project (WAMME) First Model Intercomparison Experiment. Climate Dynamics, 35, 3-27.

https://doi.org/10.1007/s00382-010-0778-2 
[10] Rutti, P.M., Williams, J.E., Hourdin, F., Guichard, F., Boone, A., Van Velthoven, P., Favot, F., Musat, I., Rummukainen, M., Dominguez, M., Gaertner, M.A., Lafore, J.P., Losada, T., Rodriguez de Fonseca, M.B., Polcher, J., Giorgi, F., Xue, Y., Bouarar, I., Law, K., Josse, B., Barret, B., Yang, X., Mari, C. and Traore, A.K. (2011) The West African Climate System: A Review of the AMMA Model Inter-Comparison Initiatives. Atmospheric Science Letters, 12, 116-122. https://doi.org/10.1002/asl.305

[11] Paeth, H., Hall, N.M.J., Gaertner, M.A., Alonso, M.D., Moumouni, S.L., Polcher, J., Ruti, P.M., Fink, A.H., Gosset, M., Lebel, T., Gaye, A.T., Rowell, D.P., MoufoumaOkia, W., Jacob, D., Rockel, B., Giorgi, F. and Rummukainen, M. (2011) Progress in Regional Downscaling of West Africa Precipitation. Atmospheric Science Letters, 12, 75-82. https://doi.org/10.1002/asl.306

[12] Giorgi, F., Jones, C. and Asrar, G.R. (2009) Addressing Climate Information Needs at the Regional Level: The CORDEX Framework. World Meteorological Organization (WMO) Bulletin, 58, 175.

[13] Nikulin, G., Jones, C., Giorgi, F., Asrar, G., Büchner, M., Cerezo-Mota, R. and Sushama, L. (2012) Precipitation Climatology in an Ensemble of CORDEX-Africa Regional Climate Simulations. Journal of Climate, 25, 6057-6078. https://doi.org/10.1175/JCLI-D-11-00375.1

[14] Gbobaniyi, B., Sarr, A., Sylla, M.B., Diallo, I., Lennard, C., Diosio, A., Diedhiou, A., Kamga, A., Klutser, N.A.B., Hewitson, B. and Lamptey, B. (2013) Climatology, Annual Cycle and Interannual Variability of Precipitation and Temperature in CORDEX Regional Climate Models Simulation over West Africa. International Journal of Climatology, 34, 2241-2257. https://doi.org/10.1002/joc.3834

[15] Klutse, N.A.B., Sylla, M.B., Diallo, I., Sarr, A., Dosio, A., Diedhiou, A., Kamga, A., Lamptey, B., Ali, A., Gbobaniyi, E.O., Owusu, K., Lennard, C., Hewitson, B., Nikulin, G., Panitz, H.J. and Büchner, M. (2015) Daily Characteristics of West African Monsoon Rainfall in CORDEX Regional Climate Models. Theoretical and Applied Climatology, 123, 1-18.

[16] Riahi, K. Gruebler, A. and Nakicenovic, N. (2007) Scenarios of Long-Term Socio-Economic and Environmental Development under Climate Stabilization. Technological Forecasting and Social Change, 74, 887-935.

https://doi.org/10.1016/j.techfore.2006.05.026

[17] Van Vuuren, D.P., Edmonds, J., Thomson, A., Riahi, K., Kainuma, M., Matsui, T., Hurtt, G.C., Lamarque, J.-F., Meinshausen, M., Smith, S., Granier, C., Rose, S.K. and Hibbard, K.A. (2011a) Representative Concentration Pathways: An Overview. Climatic Change, 109, 5-31. https://doi.org/10.1007/s10584-011-0148-Z

[18] Samuelsson, P., Jones, C.G., Willen, U., Ullerstig, A., Gollvik, S., Hansson, U., Jansson, C., Kjellström, E., Nikulin, G. and Wyser, K. (2011) The Rossby Centre Regional Climate Model RCA3: Model Description and Performance. Tellus A: Dynamic Meteorology and Oceanography, 63, 4-23. https://doi.org/10.1111/j.1600-0870.2010.00478.x

[19] Adler, R.F., Huffman, G.J., Chang, A., Ferraro, R., Xie, P., Janowiak, J., Rudolf, B., Schneider, U., Curtis, S., Bolvin, D., Gruber, A., Susskind, J., Arkin, P. and Nelkin, E. (2003) The Version 2 Global Precipitation Climatology Project (GPCP) Monthly Precipitation Analysis (1979-Present). Journal of Hydrometeorology, 4, 1147-1167. https://doi.org/10.1175/1525-7541(2003)004<1147:TVGPCP >2.0.CO;2

[20] Huffman, G.J., Adler, R.F., Morrissey, M.M., Bolvin, D.T., Curtis, S., Joyce, R., McGavock, B. and Susskind, J. (2001) Global Precipitation at One Degree Daily Resolution from Multi Satellite Observations. Journal of Hydrometeorology, 2, 36-50. https://doi.org/10.1175/1525-7541(2001)002<0036:GPAODD >2.0.CO;2 
[21] University of East Anglia Climatic Research Unit (CRU), Jones, P. and Harris, I. (2013) CRU TS3.21: Climatic Research Unit (CRU) Time-Series (TS) Version 3.21 of High Resolution Gridded Data of Month-by-Month Variation in Climate (Jan. 1901 - Dec. 2012). NCAS British Atmospheric Data Centre, Leeds.

http://badc.nerc.ac.uk/view/badc.nerc.ac.uk_ATOM_ACTIVITY_0c08abfc-f2d511e2-a948-00163e251233

[22] Taylor, K.E. (2001) Summarizing Multiple Aspects of Model Performance in a Single Diagram. Journal of Geophysical Research, 106, 7183-7192.

https://doi.org/10.1029/2000JD900719

[23] Diaconescu, E.P., Gachon, P., Scinocca, J. and Laprise, R. (2014) Evaluation of Daily Precipitationstatistics and Monsoon Onset/Retreat over Western Sahel in Multiple Data Sets. Climate Dynamics, 45, 1325-1354. https://doi.org/10.1007/s00382-014-2383-2

[24] Sivakumar, M.V.K. (1990) Exploring Rainy Season Potential from the Onset of Rains in the Sahelian Zone of West Africa. Agriculture and Forest Meteorology, 51, 321-332. https://doi.org/10.1016/0168-1923(90)90116-N

[25] Diallo, I., Sylla, M.B., Camara, M. and Gaye, A.T. (2012a) Interannual Variability of Rainfall and Circulation Features over the Sahel Based on Multiple Regional Climatemodels Simulations. Theoretical and Applied Climatology, 113, 351-362.

https://doi.org/10.1007/s00704-012-0791-y

[26] Paeth, H., Born, K., Podzun, R. and Jacob, D. (2005) Regional Dynamical Downscaling over West Africa: Model Evaluation and Comparison of Wet and Dry Years. Meteorologische Zeitschrift, 14, 349-368. https://doi.org/10.1127/0941-2948/2005/0038

[27] Diallo, I., Sylla, M.B. Giorgi, F., Gaye, A.T. and Camara, M. (2012b) Multi-Model GCM-RCM Ensemble Based Projections of Temperature and Precipitation over West Africa for the Early 21st Century. International Journal of Geophysics, 2012, Article ID: 972896. https://doi.org/10.1155/2012/972896

[28] Dosio, A. and Panitz, H.J. (2016) Climate Change Projections for CORDEX-Africa with COSMO-CLM Regional Climate Model and Differences with the Driving Global Climate Models. Climate Dynamics, 46, 1599. https://doi.org/10.1007/s00382-015-2664-4

[29] Ceron, J.P. and Gueremy, J.F. (1999) Validation of the Space-Time Variability of African Easterly Waves Simulated by the CNRM GCM. Journal of Climate, 12, 2831-2855. https://doi.org/10.1175/1520-0442(1999)012<2831:VOTSTV >2.0.CO;2

[30] Ceron, J.P., Gueremy, J.F. and Sarr, A. (2001) Synoptic Variability during West African Monsoon: Validation of Meteo-France GCM Simulations. Physics and Chemistry of the Earth, 26, 149-153.

https://doi.org/10.1016/S1464-1909(00)00232-X

[31] Tadross, M.A., Gutowski Jr., W.J., Hewitson, B.C., Jack, C. and New, M. (2006) MM5 Simulations of Interannual Change and the Diurnal Cycle of Southern African Regional Climate. Theoretical and Applied Climatology, 86, 63-80. https://doi.org/10.1007/s00704-005-0208-2

[32] Sylla, M.B., Diallo, I. and Pal, J.S. (2013b) West African Monsoon in State-of-theArt Regional Climate Models. In: Tarhule, A., Ed., Climate Variability-Regional and Thematic Patterns, Chapter 1. https://doi.org/10.5772/55140

[33] Giannini, A., Saravanan, R. and Chang, P. (2003) Oceanic Forcing of Sahel Rainfall on Interannual to Interdecadal Time Scales. Science, 302, 1027-1030.

https://doi.org/10.1126/science.1089357 
[34] Nicholson S.E. (2013) The West African Sahel: A Review of Recent Studies on the Rainfall Regime and Its Interannual Variability. ISRN Meteorology, 2013, Article ID: 453521. https://doi.org/10.1155/2013/453521

[35] Le Barbé, L., Lebel, T. and Tapsoba, D. (2002) Rainfall Variability in West Africa during the Years 1950-1990. Journal of Climate, 15, 187-202. https://doi.org/10.1175/1520-0442(2002)015<0187:RVIWAD>2.0.CO;2

[36] Sylla, M.B., Giorgi, F., Coppola, E. and Mariotti, L. (2013a) Uncertainties in Daily Rainfall over Africa: Assessment of Observation Products and Evaluation of a Regiona Climate Model Simulation. International Journal of Climatology, 33, 1805-1817. https://doi.org/10.1002/joc.3551

[37] Giorgi, F. (1990) Simulation of Regional Climate Using a Limited Area Model Nested in a General Circulation Model. Journal of Climate, 3, 941-963. https://doi.org/10.1175/1520-0442(1990)003<0941:SORCUA >2.0.CO;2

[38] McGregor, J.L. (1997) Regional Climate Modeling. Meteorology and Atmospheric Physics, 63, 105-117. https://doi.org/10.1007/BF01025367

[39] Adejuwon, J. and Odekunle, T. (2006) Variability and the Severity of the "Little Dry Season" in Southwestern Nigeria. Journal of Climate, 19, 483-493. https://doi.org/10.1175/JCLI3642.1

[40] Sultan, B. and Janicot, S. (2000) Abrupt Shift of the ITCZ over West Africa and Intra-Seasonal Variability. Geophysical Research Letters, 27, 3353-3356. https://doi.org/10.1029/1999GL011285

[41] Sultan, B. and Janicot, S. (2003) The West African Monsoon Dynamics. Part II: The "Preonset" and "Onset" of the Summer Monsoon. Journal of Climate, 16, 34073427. https://doi.org/10.1175/1520-0442(2003)016<3407:TWAMDP>2.0.CO;2

[42] Sivakumar, M.V.K., Maidouka, A. and Stern, R.D. (1993) Agroclimatoly of West Africa. 2nd Edition, International Crops Research Institute for the Semi-Arid Tropics, Patancheru, Hyderabad, 116 p.

[43] Knippertz, P. and Martin, J.E. (2005) Tropical Plumes and Extreme Precipitation in Subtropical and Tropical West Africa Quart. Journal of the Royal Meteorological Society, 131, 2337-2365. https://doi.org/10.1256/qj.04.148

[44] Fall, S., Mohanty, U.C. and Kumar, A. (2007) Application of Weather Prediction Model for Hazard Mitigation Planning: A Case Study of Heavy Off-Season Rains in Senegal. Natural Hazards, 41, 227-243. https://doi.org/10.1007/s11069-006-9033-x

[45] Giorgi, F. and Coppola, E. (2010) Does the Model Regional Bias Affect the Projected Regional Climate Change? An Analysis of Global Model Projections. Climatic Change, 100, 787-795. https://doi.org/10.1007/s10584-010-9864-Z

[46] Chalmers, N., Highwood, E.J., Hawkins, E., Sutton, R. and Wilcox, L.J. (2012) Aerosol Contribution to the Rapid Warming of Near-Term Climate under RCP 2.6. Geophysical Research Letters, 39, L18709. https://doi.org/10.1029/2012GL052848

[47] Mendelsohn, R. (2008) The Impact of Climate Change on Agriculture in Developing Countries. Journal of Natural Resources Policy Research, 1, 5-19, https://doi.org/10.1080/19390450802495882

[48] Adler, R.F., Huffman, G.J., Chang, A., Ferraro, R., Xie, P.-P., Janowiak, J., Rudolf, B., Schneider, U., Curtis, S., Bolvin, D., Gruber, A., Susskind, J., Arkin, P. and Nelkin, E. (2003) The Version-2 Global Precipitation Climatology Project (GPCP) Monthly Precipitation Analysis (1979-Present). Journal of Hydrometeorology, 4, 1147-1167. https://doi.org/10.1175/1525-7541(2003)004<1147:TVGPCP > 2.0.CO;2 
[49] Kirtman, B., Power, S.B., Adedoyin, J.A., Boer, G.J., Bojariu, R., Camilloni, I., Doblas-Reyes, F.J., Fiore, A.M., Kimoto, M., Meehl, G.A., Prather, M., Sarr, A., Schär, C., Sutton, R., van Oldenborgh, G.J., Vecchi, G. and Wang, H.J. (2013) Near-Term Climate Change: Projections and Predictability. In: Stocker, T.F., Qin, D., Plattner, G.-K., Tignor, M., Allen, S.K., Boschung, J., Nauels, A., Xia, Y., Bex, V. and Midgley, P.M., Eds., Climate Change 2013: The Physical Science Basis. Contribution of Working Group I to the Fifth Assessment Report of the Intergovernmental Panel on Climate Change. Cambridge University Press, Cambridge, United Kingdom and New York, 953-1028.

[50] Mearns, L. (2010) The Drama of Uncertainty. Climatic Change, 100, 77-85.

https://doi.org/10.1007/s10584-010-9841-6

Submit or recommend next manuscript to SCIRP and we will provide best service for you:

Accepting pre-submission inquiries through Email, Facebook, LinkedIn, Twitter, etc. A wide selection of journals (inclusive of 9 subjects, more than 200 journals)

Providing 24-hour high-quality service

User-friendly online submission system

Fair and swift peer-review system

Efficient typesetting and proofreading procedure

Display of the result of downloads and visits, as well as the number of cited articles

Maximum dissemination of your research work

Submit your manuscript at: http://papersubmission.scirp.org/

Or contact ajcc@scirp.org 